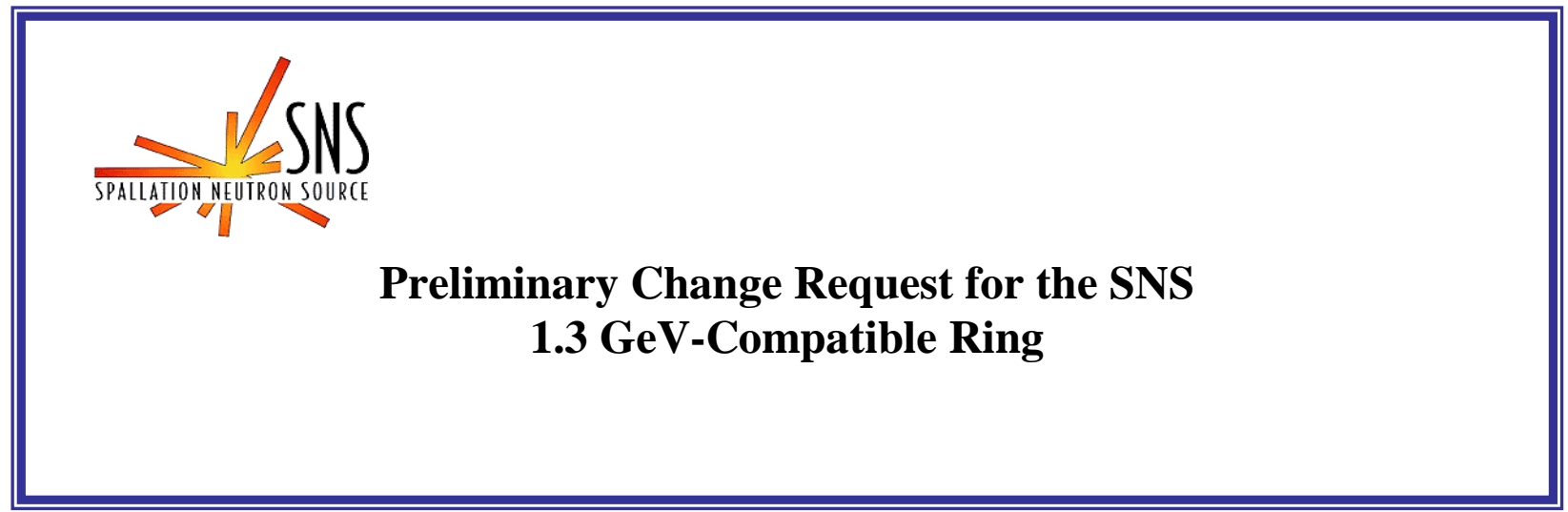

BNL/SNS TECHNICAL NOTE

NO. 076

J. Wei (Editor)

May 4, 2000

COLLIDER-ACCELERATOR DEPARTMENT

BROOKHAVEN NATIONAL LABORATORY

UPTON, NEW YORK 11973 


\section{Preliminary Change Request for the SNS 1.3 GeV-Compatible Ring}

(May 4, 2000) 


\section{Preface}

During the second Accelerator System Advisory Committee review of the Spallation Neutron Source (SNS) Project on December 1999, a feasibility study was presented on using superconducting linac to deliver $1 \mathrm{GeV}$ beam for the SNS. With the accelerating gradient possibly being improved over the first few years of operation, the superconducting linac has the potential to reach $1.3 \mathrm{GeV}$ beam energy. The SNS Project Office thus suggested that a study be performed to modify the accumulator ring so that it can not only deliver $2 \mathrm{MW}$ beam power at $1 \mathrm{GeV}$ but is also compatible with $1.3 \mathrm{GeV}$ operation.

This report documents study results based on which a change request is to be made for the SNS ring. The goal of the study is to re-design the ring to be compatible with a higher injection energy of $1.3 \mathrm{GeV}$, while at the same time keeping the same level of maintainability and performance at $1 \mathrm{GeV}$ with $2 \mathrm{MW}$ beam power. Since the SNS project is already in its construction phase, every effort is made to minimize the impact on project cost and schedule. 


\section{Contents}

1 Overview $\quad 5$

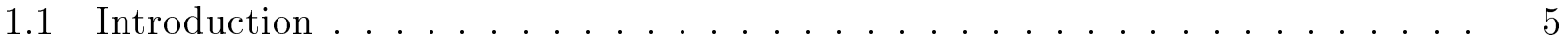

1.2 Re-design Issues . . . . . . . . . . . . . . . . . . . . . . . . . . . . . . . . . . . . . . . . .

1.3 Acknowledgments . . . . . . . . . . . . . . . . 7

2 Justification of Changes for $1 \mathrm{GeV}$ Operation $\quad 8$

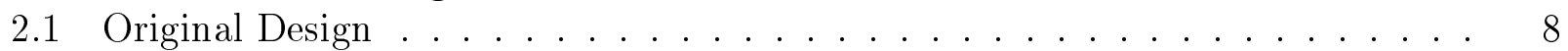

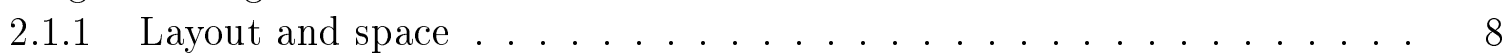

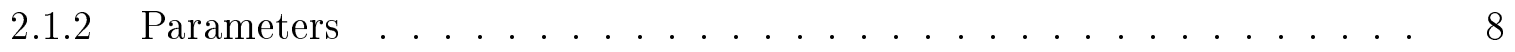

2.1.3 Acceptance and momentum aperture . . . . . . . . . . . 12

2.1.4 Lattice and working points . . . . . . . . . . . . . . . . 12

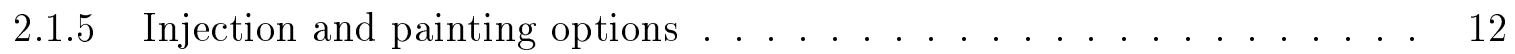

2.1.6 Collimation and loss distribution . . . . . . . . . . . 15

2.1.7 Extraction . . . . . . . . . . . . . . . 15

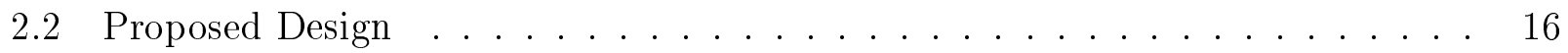

2.2.1 Layout and space . . . . . . . . . . . . . . . 16

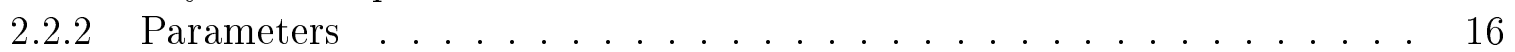

2.2.3 Acceptance and momentum aperture . . . . . . . . . . . . 16

2.2 .4 Lattice and working points . . . . . . . . . . . . . 22

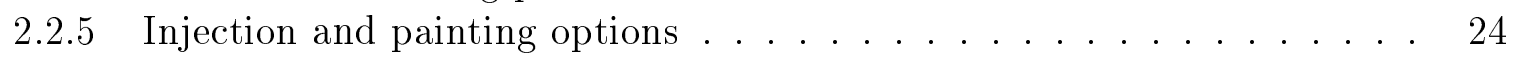

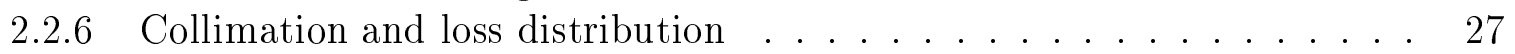

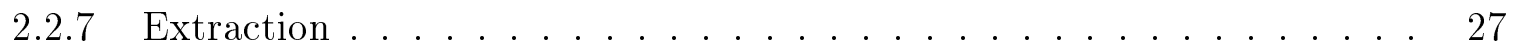

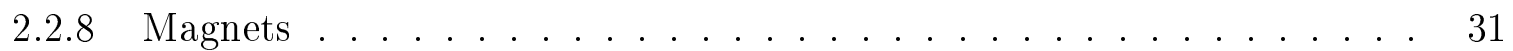

2.2.9 Expected magnetic errors and misalignments . . . . . . . . . . . . 35

2.2.10 Dynamic aperture . . . . . . . . . . . . . . 35

2.2.11 Impedance and instabilities . . . . . . . . . . . . . . 35

2.3 Changes and Benefits . . . . . . . . . . . . . . . . 38

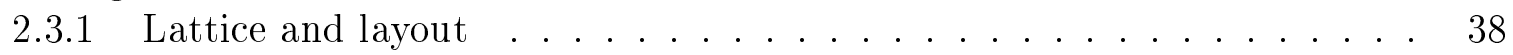

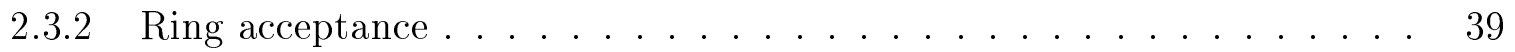

2.3.3 Space-charge tune shift and beam tail . . . . . . . . . . . . . . . 39

2.3.4 Collimation efficiency and uncontrolled beam loss . . . . . . . . . . . . . 39

2.3.5 Ring magnets and power supplies . . . . . . . . . . . . . 39

2.3.6 Injection and extraction . . . . . . . . . . . . . . . 39

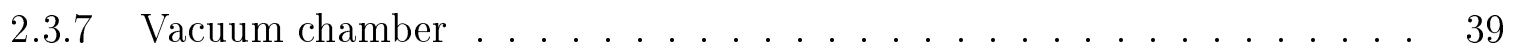

2.3 .8 HEBT . . . . . . . . . . . . . . . . . . 40

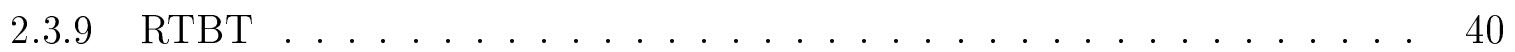

3 Impact on the Front End and Linac $\quad 41$

4 Impact on the Target $\quad 42$

5 Impact on the Ring WBS 43 
6 Future Changes for $1.3 \mathrm{GeV}$ Operation $\quad 44$

6.1 Changes and Benefits . . . . . . . . . . . . . . . . . . . . . . . . . . . . . . 44

6.1 .1 Power supplies . . . . . . . . . . . . . . . . . . . 45

6.1 .2 Injection . . . . . . . . . . . . . . . . 45

6.1 .3 Collimation . . . . . . . . . . . . . . 45

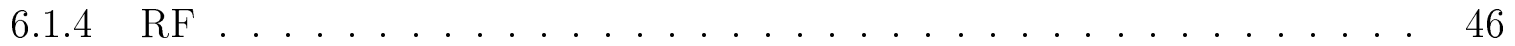

6.1 .5 Extraction .................... 46

$\begin{array}{lll}7 & \text { Summary } & 47\end{array}$ 


\section{Overview}

\section{$1.1 \quad$ Introduction}

The Spallation Neutron Source (SNS) is based on an accelerator producing an average beam power of $2 \mathrm{MW}$ at a repetition rate of $60 \mathrm{~Hz}$. The accelerator complex [1] consists of the source and the front end, a $1 \mathrm{GeV}$ full-energy Linac, a single accumulator ring and its transfer lines, and the target. In October 1999, the ring layout is changed from alpha configuration to omega configuration, and the ring lattice is changed from all-FODO to FODO/doublet hybrid lattice [2]. After the second Accelerator System Advisory Committee review on December 1999, the SNS Project Office instructed the submission of a change request for a superconducting linac delivering $1 \mathrm{GeV}$ beam, and an accumulator ring that is designed for $1 \mathrm{GeV}$ operation but compatible to $1.3 \mathrm{GeV}$ injection energy. This report documents the design study for the 1.3 GeV-compatible ring.

\section{$1.2 \quad$ Re-design Issues}

Reliability and maintainability are of primary importance to the SNS facility. Based on operational experience at LAMPH [3], AGS, and AGS Booster [4], hands-on maintenance demands that the average uncontrolled beam loss be limited to about 1 to $2 \mathrm{~W}$ of beam power per tunnel meter. For the accumulator ring with a circumference of more than 200 meters, this corresponds to an average uncontrolled beam loss of about $10^{-4}$ at $1 \mathrm{GeV}$ beam energy [5].

With $\mathrm{H}^{-}$beam transfered from the linac at $1.3 \mathrm{GeV}$ kinetic energy, the maximum magnetic field in the HEBT and ring injection region must be reduced from what is designed for $1 \mathrm{GeV}$ energy. Had the same magnets being used, with the magnetic field increased by $20 \%$ to accommodate the increased beam rigidity, the uncontrolled beam loss caused by the Lorentz stripping would be about $6 \times 10^{-4}$ per meter. In order to keep stripping loss to a level of about $10^{-7}$ per meter, same as that presently designed for $1 \mathrm{GeV}$ operation, magnetic lengths of the HEBT and ring injection septum need to be increased by about $40 \%$. Consequently, the length of HEBT line and the circumference of the ring are increased [6].

Energy dependence of $\mathrm{H}^{0}$ stripping at various excited states causes another complication. Both the injection field and the field at which the stripping foil is located have to be chosen so that $\mathrm{H}^{0}$ of state $n=5$ and above is fully stripped by the first stripping foil to become circulating beam, and $\mathrm{H}^{0}$ of state $n=4$ and below is stripped only by the second stripping foil to the beam dump. Extra space needs to be reserved in the injection region for future replacement of two injection dipoles for $1.3 \mathrm{GeV}$ operation.

Comparing with $1 \mathrm{GeV}$ beam, the stopping length for $1.3 \mathrm{GeV}$ beam is about $60 \%$ longer. The yield of secondary neutron from the primary proton is also increased. Extra space needs also to be reserved in beam collimation section to accommodate longer collimators at $1.3 \mathrm{GeV}$.

The RF frequency needs to be reduced to accommodate the increased ring circumference, and to be adjustable for the variable energy. At $1.3 \mathrm{GeV}$, extra RF voltage is also needed to compensate possible electron cloud effects.

Although magnet power supplies are still designed for $1 \mathrm{GeV}$ beam, the magnets themselves 
have to be compatible for an increase of $20 \%$ magnetic field. Extra amount of steel and extra turns of coils are designed to avoid saturation and to satisfy engineering conditions.

For the ring extraction, the length of the Lambertson magnet is increased by $15 \%$. Extra space is reserved for addition of two extra extraction kickers for $1.3 \mathrm{GeV}$ operation.

Since the SNS project is already in construction since October 1998, every effort is made to minimize the impact of lattice change on project cost and schedule. The machine periodicity and working points are kept the same. The lattice and geometrical dimensions of the ring arc are also kept unchanged. With perfect matching between the arcs and straights, only straight section quadrupoles and correctors need to be modified to accommodate increased beam size caused by the increased ring straight lengths. 


\subsection{Acknowledgments}

\section{Contributors:}

D. Abell, J. Beebe-Wang, M. Blaskiewicz, J. Brodowski, P. Cameron, N. Catalan-Lasheras, G. Danby, A. Fedotov, C. Gardner, H.C. Hseuh, J. Jackson, Y.Y. Lee, H. Ludewig, N. Malitsky, J. Negrin, C-I. Pai, I. Papaphilippou, D. Raparia, J. Sandberg, N. Tsoupas, J. Tuozzolo, J. Wei, W.T. Weng, A. Zaltsman, S. Y. Zhang

\section{Acknowledgments:}

J. Alessi, Y. Cho, J.D. Galambos, R.L. Gluckstern, D. Kaltchev, R. Kustom, J.B. Jeanneret, D. Lowenstein, A.U. Luccio, S. Machida, W. Meng, M. Nekulak, C. Prior, J-L. Mi, K. Reece, G. Rees, H. Schonauer, R. Talman, J.G. Wang, R. Witkover, and the SNS team at the Brookhaven National Laboratory.

\section{Editor:}

J. Wei 


\section{Justification of Changes for $1 \mathrm{GeV}$ Operation}

The Spallation Neutron Source is based on an accelerator producing an average beam power of $2 \mathrm{MW}$ at a repetition rate of $60 \mathrm{~Hz}$. The accelerator complex consists of an ion source and a front end, a Linac, and an accumulator ring and its transfer lines. The proposed change request is on the ring and its transfer lines, proposing to change the ring and transfer lines to accommodate for $1.3 \mathrm{GeV}$ beam.

This section describes changes and justification for $1 \mathrm{GeV}$ operation. Further changes necessary for $1.3 \mathrm{GeV}$ operation is discussed in Section 6 .

\subsection{Original Design}

As shown in Figure 1, the ring and transfer lines form the so-called omega configuration, where HEBT and RTBT transfer lines no longer cross each other, thus simplifying operation and maintenance [2]. The ring lattice is four-fold symmetric with each super-period containing one FODO arc section and one doublet straight section. The arc section consists of four 8-meter long FODO cells, each with a horizontal betatron phase advance of 90 degrees. The dispersion-free straight section consists of one 9.04-meter and two 5.45-meter uninterrupted drift spaces.

The ring has 32 arc dipole magnets and 52 quadrupole magnets. The inscribed diameters are $26 \mathrm{~cm}$ for the 24 quadrupoles located in the straight sections and the high-dispersion locations of the arcs, and $21 \mathrm{~cm}$ for the other 28 quadrupoles.

\subsubsection{Layout and space}

Figure 2 shows the schematic layout of the ring. The four straight sections are mainly designed for beam injection, beam collimation, extraction, and RF systems. Each of the 4 lattice period contains a straight section that has one $9.04 \mathrm{~m}$ and two $5.48 \mathrm{~m}$ drift spaces. The total straight section length is about 80 meters. For each drift space, the "overhead" taken by correctors, BPMs, vacuum pumps, bellows, flanges, etc. is about 1.5 meters. The total usable length is about 62 meters. Each period has $4 \mathrm{~m}-7.5 \mathrm{~m}-4 \mathrm{~m}$ structure. The total unclaimed dispersion-free drift space is about 14 meters, among which 8 meters are located in the collimation section. For the arc section, the layout is mirror-symmetric with respect to the middle of the arc to minimize vacuum chamber type.

\subsubsection{Parameters}

Table 1 lists major machine and beam parameters for the original hybrid lattice ring. The nominal working point in the transverse tune space $\left(Q_{x}, Q_{y}\right)$ is $(6.30,5.80)$, with the horizontal and vertical tunes split by half a unit. The lattice is tunable over a range of more than one unit. Three alternative working points are $(6.30,5.27),(5.82,4.80)$ and $(5.82,5.80)$. The final transverse beam distribution is quasi-uniform in a elliptical area satisfying the required current density limit of below $0.25 \mathrm{~A} / \mathrm{m}^{2}$. 


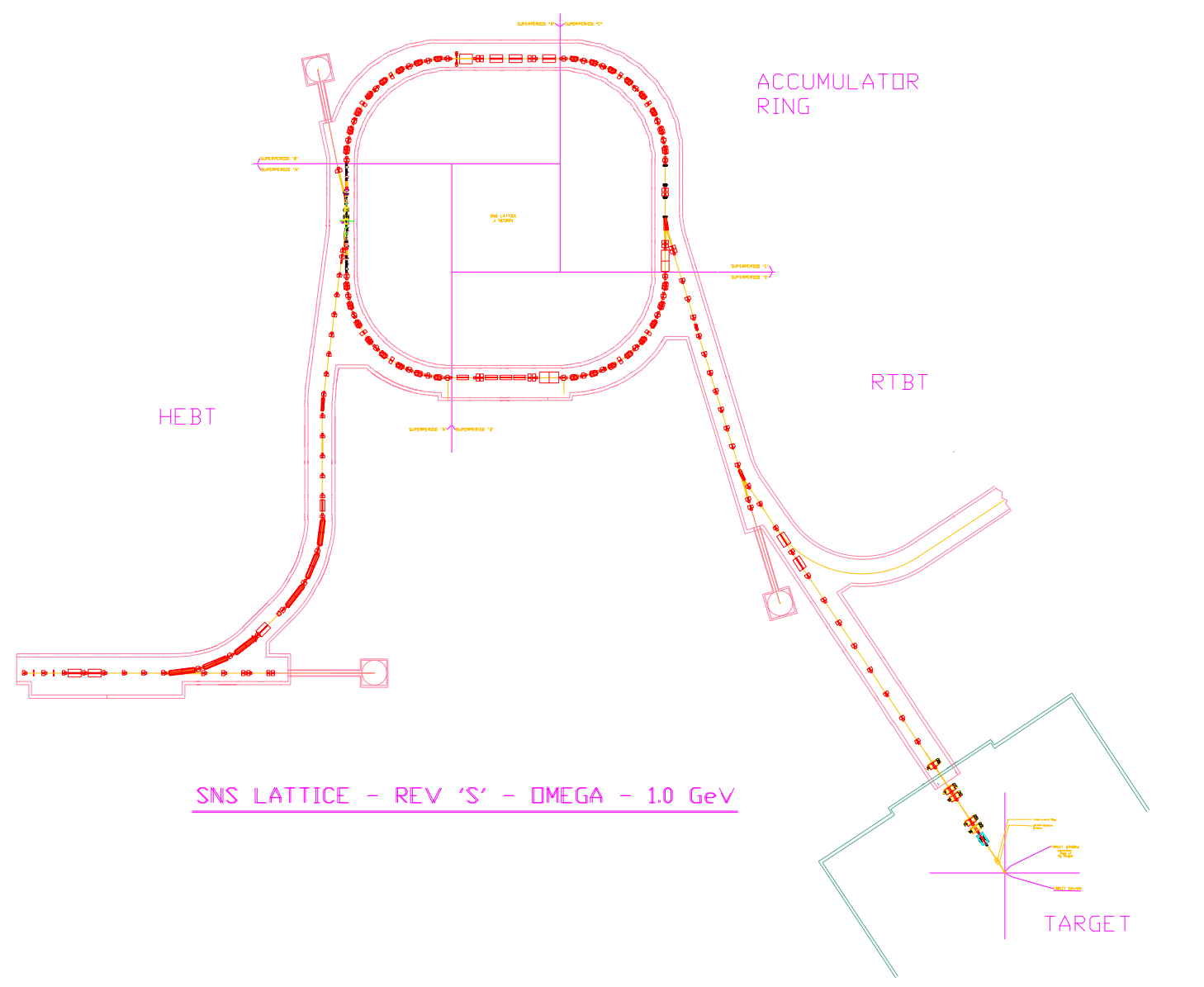

Figure 1: Layout of the original FODO-doublet hybrid lattice in the omega configuration for the Spallation Neutron Source ring. 


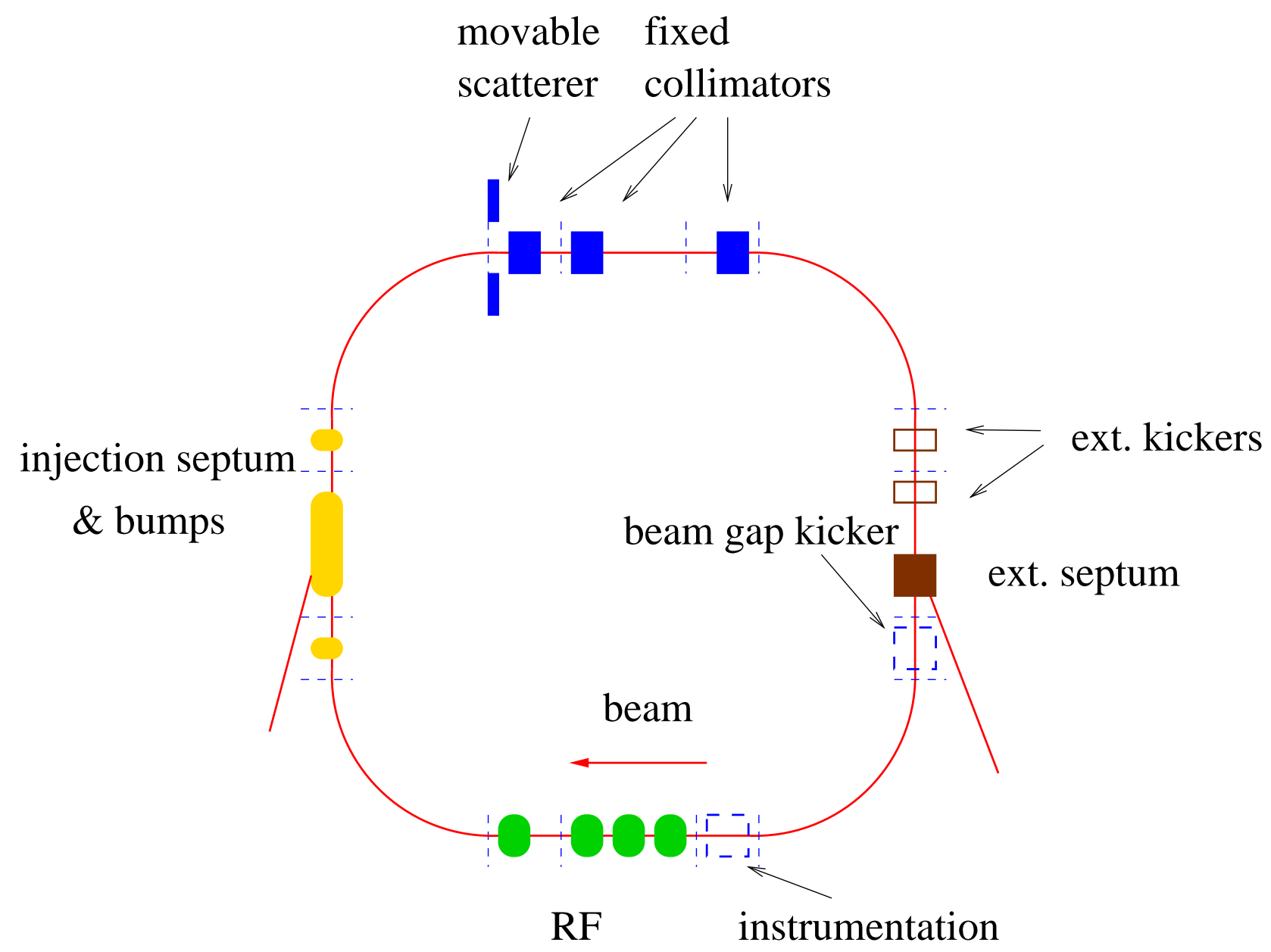

Figure 2: Schematic layout of the original SNS ring in the omega configuration. 
Table 1: Major machine parameters for the original hybrid lattice Spallation Neutron Source ring.

\begin{tabular}{lll}
\hline Quantity & Value & unit \\
\hline Circumference & 220.88 & $\mathrm{~m}$ \\
Average radius & 35.154 & $\mathrm{~m}$ \\
Injection energy & 1 & $\mathrm{GeV}$ \\
Extraction energy & 1 & $\mathrm{GeV}$ \\
Beam power & 2 & $\mathrm{MW}$ \\
Repetition rate per ring & 60 & $\mathrm{~Hz}$ \\
Number of proton & 2.08 & $10^{14}$ \\
Ring dipole field & 0.7406 & $\mathrm{~T}$ \\
RF harmonic & 1,2 & \\
Peak RF voltage, $h=1$ & 40 & $\mathrm{kV}$ \\
Peak RF voltage, $h=2$ & 20 & $\mathrm{kV}$ \\
Normalized emittance & 289 & $\pi \mathrm{mm} \mathrm{mr}$ \\
Unnormalized emittance (99\%) & $160-240$ & $\pi \mathrm{mm} \mathrm{mr}$ \\
Betatron acceptance & 480 & $\pi \mathrm{mm} \mathrm{mr}$ \\
Momentum acceptance (full beam) & \pm 2 & $\%$ \\
Momentum acceptance (zero amplitude) & \pm 3.8 & $\%$ \\
Magnetic rigidity, $B \rho$ & 5.6575 & $\mathrm{Tm}$ \\
Bending radius, $\rho$ & 7.1301 & $\mathrm{~m}$ \\
Horizontal tune & $5.8-6.8$ & \\
Vertical tune & $4.8-5.8$ & \\
Transition energy, $\gamma_{T}$ & 4.95 & \\
Horizontal natural chromaticity & -7.5 & \\
Vertical natural chromaticity & -6.3 & \\
Number of super-period & 4 & \\
Arc lattice & 4 FODO cells & \\
Arc cell length & 8 & $\mathrm{~m}$ \\
Straight section lattice & 2 doublets & \\
Straight section drift length & $9.04,2 \times 5.45$ & $\mathrm{~m}$ \\
\hline & & \\
\hline
\end{tabular}




\subsubsection{Acceptance and momentum aperture}

The acceptance of the ring is $480 \pi \mathrm{mm} \cdot \mathrm{mr}$ in the transverse directions for particles of relative momentum deviation up to $\pm 1 \%$. The injection area is designed to accommodate both anticorrelated and correlated painting schemes. The total transverse emittance is from 160 to 240 $\pi \mathrm{mm} \cdot \mathrm{mr}$ resulting in a space-charge tune shift of about 0.15 .

The two-stage collimation is performed at an acceptance from about 225 to $275 \pi \mathrm{mm} \cdot \mathrm{mr}$. The estimated beam tail at $225 \pi \mathrm{mm} \cdot \mathrm{mr}$ is about $2 \times 10^{-3}$, and the collimation efficiency is about $95 \%$. The total uncontrolled beam loss is about $10^{-4}$.

The full momentum momentum spread is $\pm 0.7 \%$. The momentum acceptance provided by the RF system of $40 \mathrm{kV}$ voltage (harmonic $h=1$ ) is $\pm 1 \%$. The physical aperture of the machine allows a momentum acceptance of more than $\pm 2 \%$ for a beam of $160 \pi \mathrm{mm} \cdot \mathrm{mr}$ unnormalized emittance. In order to reach this value, chromatic sextupoles need to be activated to correct off-momentum optical mismatch. Figure 3 shows the envelope of $480 \pi \mathrm{mm} \cdot \mathrm{mr}$ acceptance at momentum deviation of $1 \%$ (upper), and $160 \pi \mathrm{mm} \cdot \mathrm{mr}$ acceptance at momentum deviation of $2 \%$ (bottom), respectively, for the circulating beam. The acceptance of the extraction channel is $400 \pi \mathrm{mm} \cdot \mathrm{mr}$, and the acceptance of the RTBT is $480 \pi \mathrm{mm} \cdot \mathrm{mr}$.

\subsubsection{Lattice and working points}

At the nominal working point, the arc and the straight section lattice $\beta$ function is matched, ensuring lowest possible $\beta$ function in the arc for given cell length. Cell lengths of the arc and the straight sections are determined by the requirements of minimum space for injection, extraction and collimation, a low maximum $\beta$ function $\left(\beta_{\max }\right)$, a low $\beta_{\max }$ to $\beta_{\min }$ ratio, and arc-straight matching. In addition, the horizontal betatron phase advance is 360 degrees across each arc section so that the dispersion function is zero in all the straight sections. The FODO arc structure is flexible for both chromatic correction and resonance corrections, while the long straight sections are flexible for injection and collimation. There is one power supply for the arc dipoles, and five power supplies for the lattice quadrupoles. Chromatic sextupoles are planned to be powered by four families of power supplies for nonlinear chromatic adjustments.

The FODO-doublet hybrid structure is flexible in tune adjustment for about 1 unit in both the horizontal and vertical directions. The alternative working points are $(6.30,5.27),(5.82$, $4.80)$ and $(5.82,5.80)$. Figures 4 shows the lattice functions for one super-period of the ring for the nominal working point.

\subsubsection{Injection and painting options}

With the long straight section provided by the doublets, beam injection is essentially decoupled from lattice tuning. The fixed injection chicane is located between two nearby doublet quadrupole pairs. Programmable kickers are planned for the flexibility of dynamic orbit bumps for injection painting. 

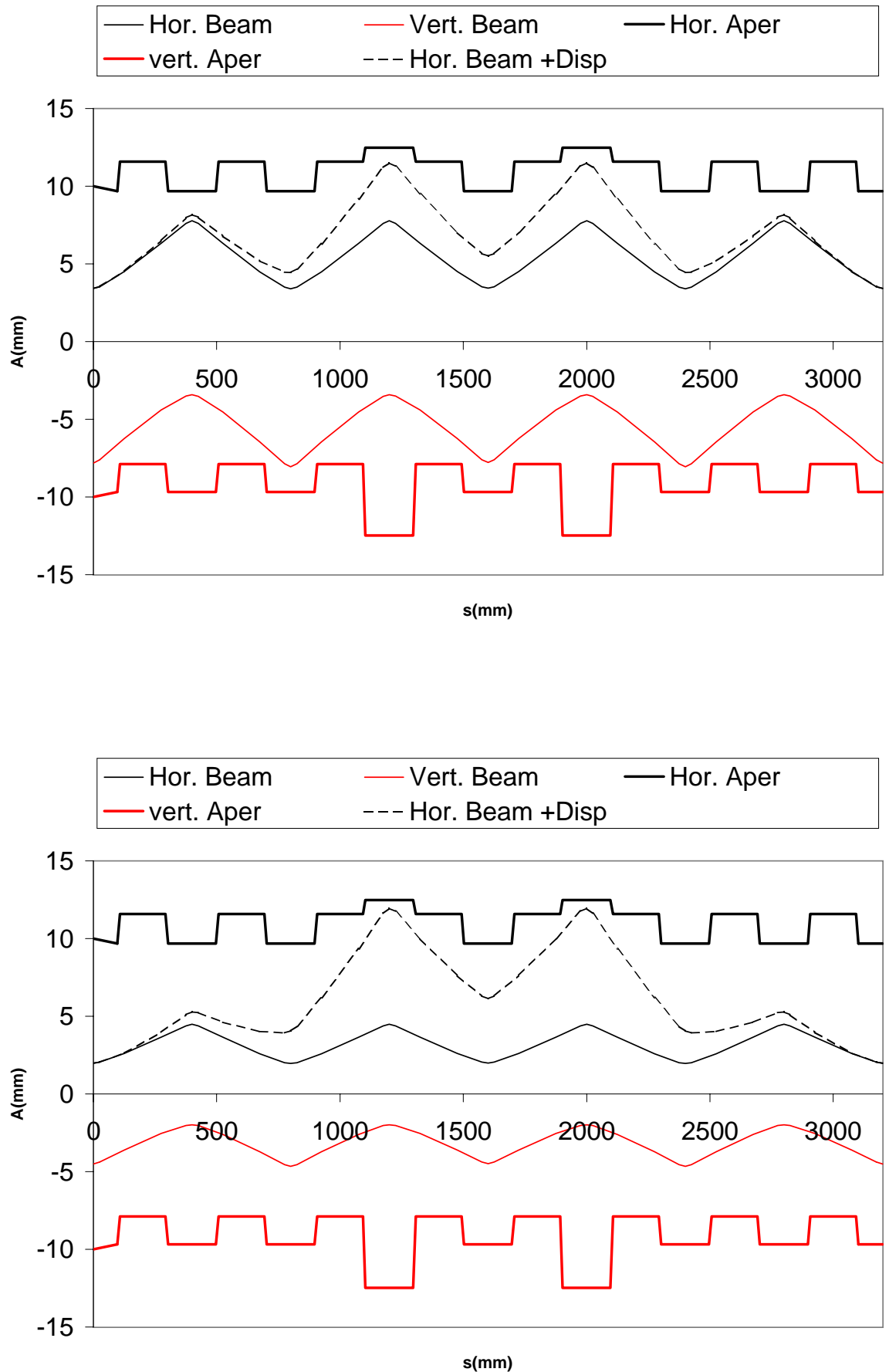

Figure 3: Envelope of $480 \pi \mathrm{mm} \cdot \mathrm{mr}$ at momentum deviation of $1 \%$ (upper), and $160 \pi \mathrm{mm} \cdot \mathrm{mr}$ at momentum deviation of $2 \%$ (bottom), in comparison with the vacuum chamber aperture in the arc. The solid lines indicate on-momentum value, and the dashed lines indicate offmomentum value. 


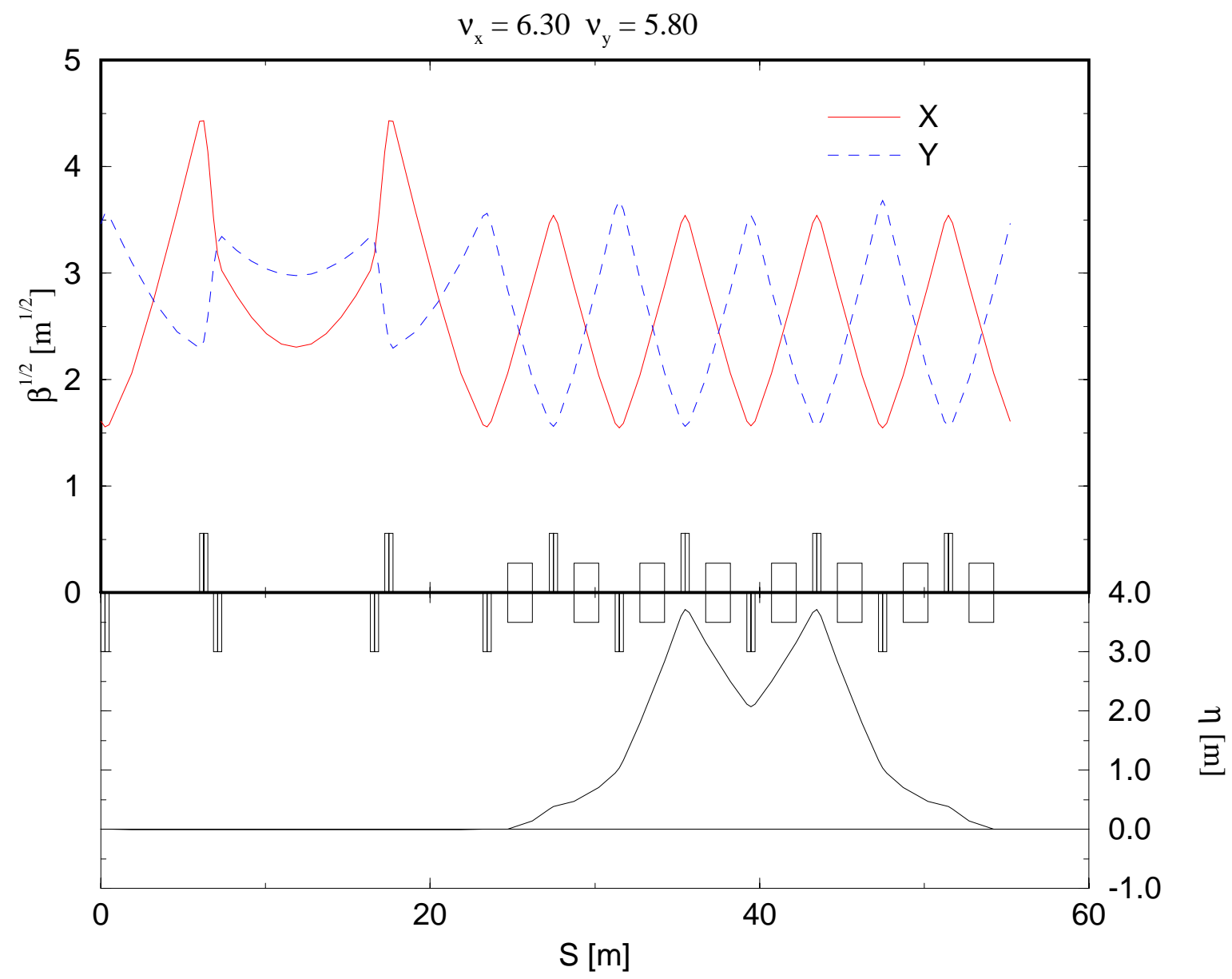

Time: Mon Jun 7 12:08:18 1999 Last file modify time: Mon Jun 7 12:09:05 1999

Figure 4: Lattice functions at tunes $\left(Q_{x}, Q_{y}\right)$ of $(6.30,5.80)$ for one super-period of the original hybrid-lattice SNS ring. 


\subsubsection{Collimation and loss distribution}

Immediately following the injection section is the multi-stage beam collimation section. This section consists of movable primary scatterers and two self-shielded collimators. At a design ring acceptance of $480 \pi \mathrm{mm} \cdot \mathrm{mr}$, the expected collimation efficiency is about $95 \%$. Beam residual in the gap between subsequent Linac bunches is cleaned by the beam-in-gap (BIG) kicker together with the multi-stage collimation system.

\subsubsection{Extraction}

The accumulated beam in the SNS ring will form a single bunch $~ 590$ ns long, with a gap of $250 \mathrm{~ns}$. Extraction of the accumulated beam will happen soon after the injection process is completed (few hundred revolutions). and the beam will be extracted from the accumulator ring in a single beam revolution, and will last $\sim 842 \mathrm{~ns}$. The maximum extraction rate will be $60 \mathrm{~Hz}$. 


\subsection{Proposed Design}

The proposed layout is again in omega configuration, as shown in Figure 5. The bending radius of the $90^{\circ}$ achromat bend of the HEBT is increased due to the reduced dipole field. The HEBT length becomes 162 meters, 25 meters longer than the original. The length of the RTBT is assumed unchanged at 150 meters.

The ring lattice is four-fold symmetric with each super-period containing one FODO arc section and one doublet straight section. The arc section consists of four 8-meter long FODO cells, each with a horizontal betatron phase advance of 90 degrees. The dispersion-free straight section consists of one 12.5-meter and two 6.85-meter uninterrupted drift spaces. The increase in ring straight length results in an increase in ring circumference from 220.88 to 248.0 meters.

The ring has 32 arc dipole magnets and 52 quadrupole magnets. The inscribed diameters are $30 \mathrm{~cm}$ for the 16 quadrupoles located in the straights, $26 \mathrm{~cm}$ for the 8 quadrupoles located at high-dispersion areas of the arcs, and $21 \mathrm{~cm}$ for the other 28 quadrupoles.

\subsubsection{Layout and space}

Figure 6 shows the schematic layout of the ring. The four straight sections are mainly designed for beam injection, beam collimation, extraction, and RF systems. All four RF cavities (three $h=1$, one $h=2$ ) are located in the same drift space. Figure 7 shows the layout of the lattice magnets (dipole, quadrupole, sextupole, and correctors) in one of the four lattice super-periods. Dipole correctors in both the arc and straight sections are used for misalignment closed orbit correction. The sextupoles in the arc sections are used for chromaticity adjustment, off-momentum optics matching, and momentum aperture improvement. The multi-layer correctors in the straight sections are used for resonance corrections.

Each of the 4 lattice period contains a straight section that has one $12.50 \mathrm{~m}$ and two 6.85 $\mathrm{m}$ drift spaces. The total straight section length is about 104.8 meters. For each drift space, the "overhead" taken by correctors, BPMs, vacuum pumps, bellows, flanges, etc. is about 1.6 meters. The total usable length is about 85 meters. Each period has $5.2 \mathrm{~m}-11 \mathrm{~m}-5.2 \mathrm{~m}$ structure. The total unclaimed drift space is adequate for an upgrade to a $1.3 \mathrm{GeV}$ machine.

\subsubsection{Parameters}

Table 2 lists major machine and beam parameters for the proposed $1.3 \mathrm{GeV}$-compatible ring. The nominal working point in the transverse tune space $\left(Q_{x}, Q_{y}\right)$ is $(6.30,5.80)$, with the horizontal and vertical tunes split by half a unit. The lattice is tunable over a range of more than one unit. Three alternative working points are $(6.30,5.27),(5.82,4.80)$ and $(5.82$, 5.80). The final transverse beam distribution is quasi-uniform in a elliptical area satisfying the required current density limit of below $0.25 \mathrm{~A} / \mathrm{m}^{2}$.

\subsubsection{Acceptance and momentum aperture}

The acceptance of the ring is $480 \pi \mathrm{mm} \cdot \mathrm{mr}$ in the transverse directions for particles of relative momentum deviation up to $\pm 1 \%$. The injection area is designed to accommodate both anticorrelated and correlated painting schemes, as shown in Figure 8. With anti-correlated or 


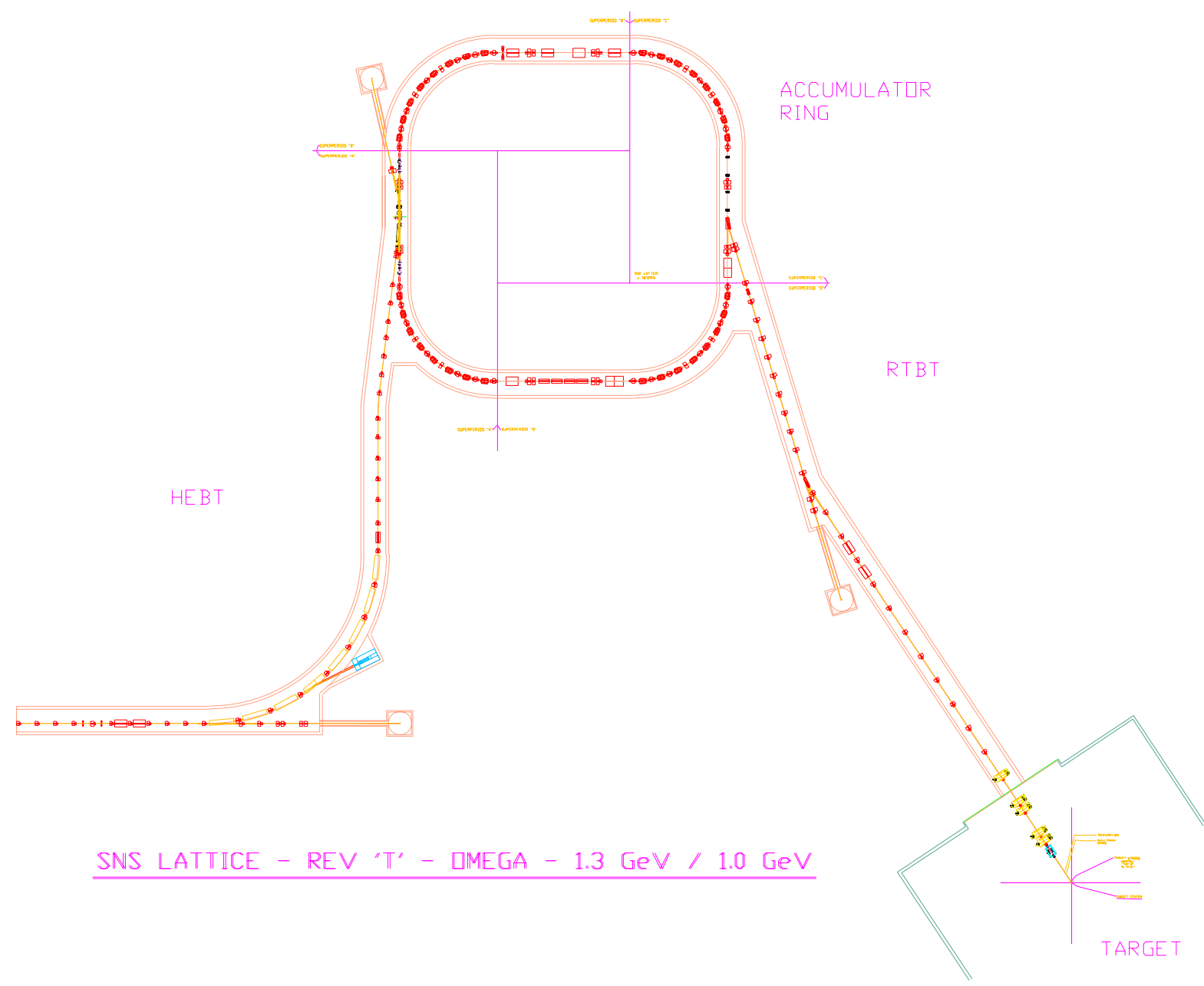

Figure 5: Layout of the proposed $1.3 \mathrm{GeV}$-compatible lattice for the Spallation Neutron Source ring. 


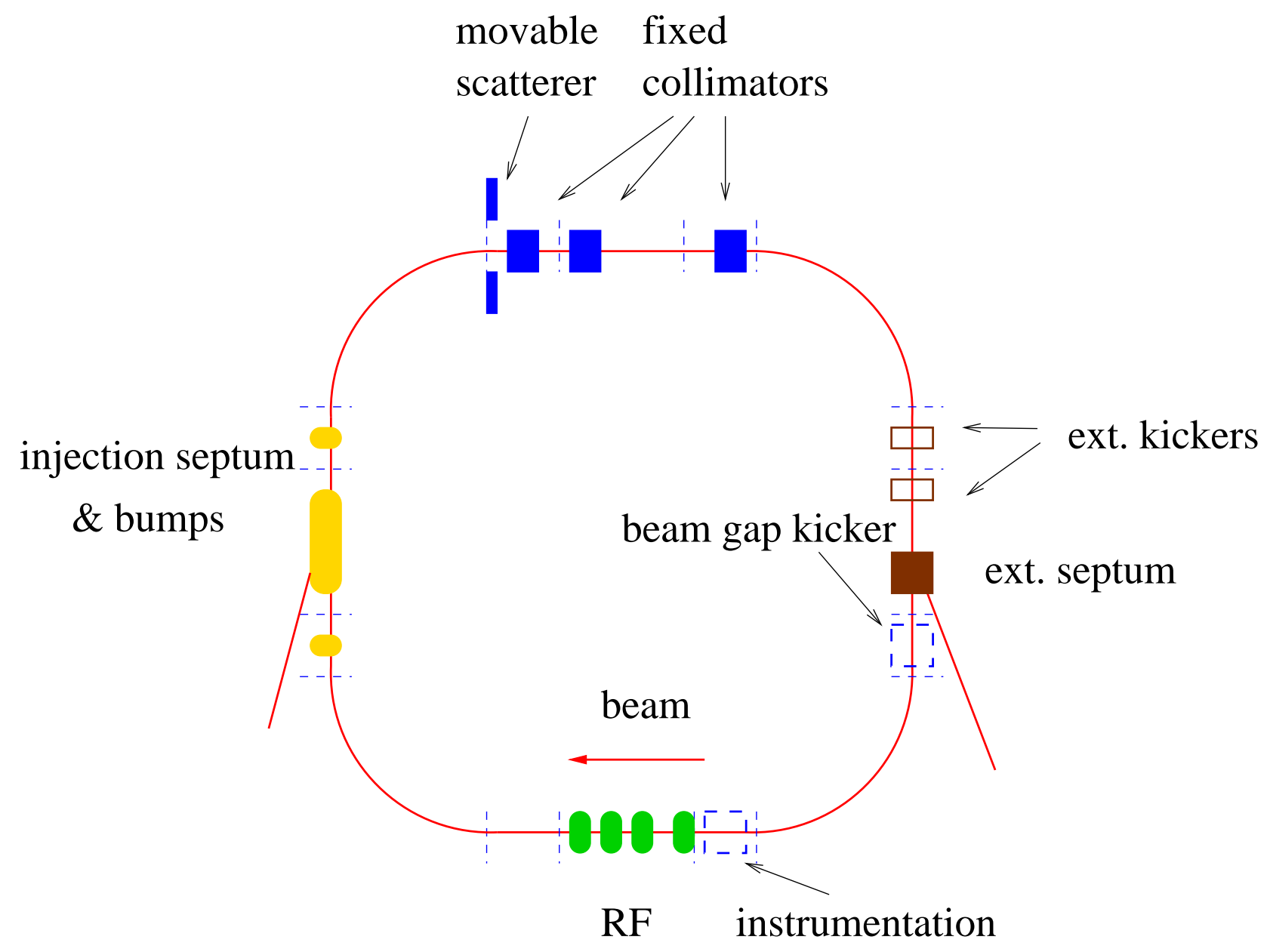

Figure 6: Schematic layout of the proposed 1.3 GeV-compatible SNS ring. 


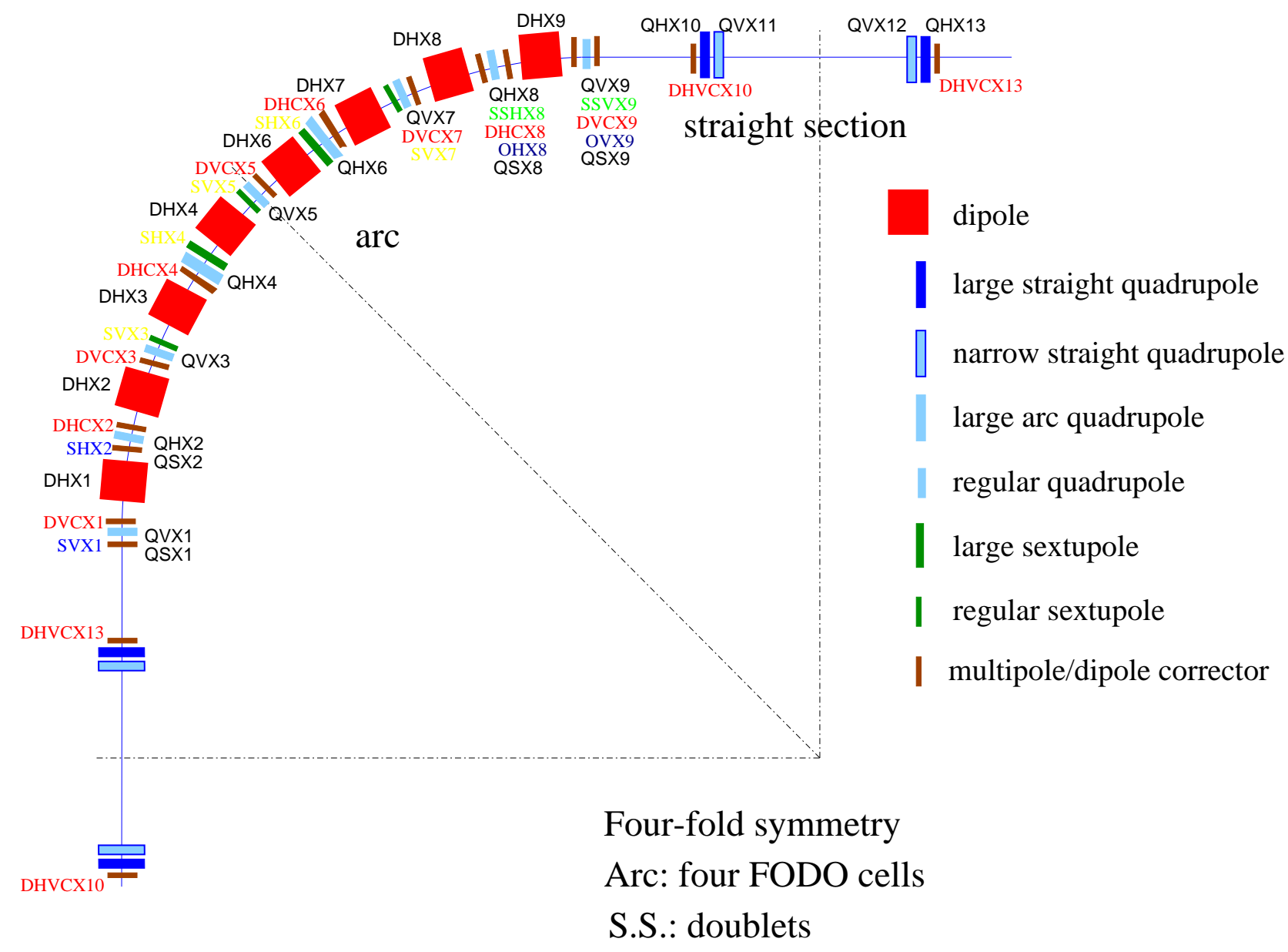

Figure 7: Schematic layout showing dipole, quadrupole, sextupole, and corrector magnets of one lattice super-period. 
Table 2: Major machine parameters for the proposed $1.3 \mathrm{GeV}$-compatible Spallation Neutron Source ring operating at $1 \mathrm{GeV}$ (nominal) and $1.3 \mathrm{GeV}$ (upgrade), respectively.

\begin{tabular}{llll}
\hline Quantity & $1 \mathrm{GeV}$ & $1.3 \mathrm{GeV}$ & $\mathrm{Unit}$ \\
\hline Circumference & 248.0 & 248.0 & $\mathrm{~m}$ \\
Average radius & 39.47 & 39.47 & $\mathrm{~m}$ \\
Injection energy & 1.0 & 1.3 & $\mathrm{GeV}$ \\
Extraction energy & 1.0 & 1.3 & $\mathrm{GeV}$ \\
Beam power & 2 & $2-4$ & $\mathrm{MW}$ \\
Repetition rate per ring & 60 & 60 & $\mathrm{~Hz}$ \\
Injection turns & 1060 & 1100 & \\
Ring filling time & 1.0 & 1.0 & $\mathrm{~ms}$ \\
Number of proton & 2.0 & $1.6-3.3$ & $10^{14}$ \\
Ring dipole field & 0.792 & 0.950 & $\mathrm{~T}$ \\
RF harmonic & 1,2 & 1,2 & \\
Peak rf voltage, $h=1$ & 40 & $40-60$ & $\mathrm{kV}$ \\
Peak rf voltage, $h=2$ & 20 & 20 & $\mathrm{kV}$ \\
RF frequency, $h=1$ & 1.058 & 1.098 & $\mathrm{MHz}$ \\
Revolution period & 945.4 & 911.1 & $\mathrm{~ns}$ \\
Bunch length (full) & 645 & 645 & $\mathrm{~ns}$ \\
Normalized emittance & 347 & 347 & $\pi \mathrm{mm} \mathrm{mr}$ \\
Unnormalized emittance (99\%) & $160-240$ & $160-240$ & $\pi \mathrm{mm} \mathrm{mr}$ \\
Betatron acceptance & 480 & 480 & $\pi \mathrm{mm} \mathrm{mr}$ \\
Momentum acceptance (full beam) & \pm 2 & \pm 2 & $\%$ \\
Momentum acceptance (zero amplitude) & \pm 3.8 & \pm 3.8 & $\%$ \\
Magnetic rigidity, $B \rho$ & 5.6575 & 6.7777 & $\mathrm{Tm}$ \\
Bending radius, $\rho$ & 7.1301 & 7.1301 & $\mathrm{~m}$ \\
Horizontal tune & 6.32 & 6.32 & \\
Vertical tune & 5.80 & 5.80 & \\
Transition energy, $\gamma_{T}$ & 5.25 & 5.25 & \\
Slip factor, $\eta$ & -0.198 & -0.139 & \\
Relativistic factors, $\beta, \gamma$ & $0.875,2.066$ & $0.908,2.386$ & \\
Horizontal natural chromaticity & -7.7 & -7.7 & \\
Vertical natural chromaticity & -6.4 & -6.4 & \\
Number of superperiod & 4 & 4 & $\mathrm{~m}$ \\
Arc lattice & $4 \mathrm{FODO}$ cells & $4 \mathrm{FODO}$ cells & \\
Arc cell length & 8 & 8 & $\mathrm{~m}$ \\
Straight section lattice & 2 doublets & 2 doublets & \\
Straight section drift length & $12.50,2 \times 6.85$ & $12.50,2 \times 6.85$ & $\mathrm{~m}$ \\
Electron bounce frequency & $100-175$ & $150-250$ & $\mathrm{MHz}$ \\
\hline
\end{tabular}




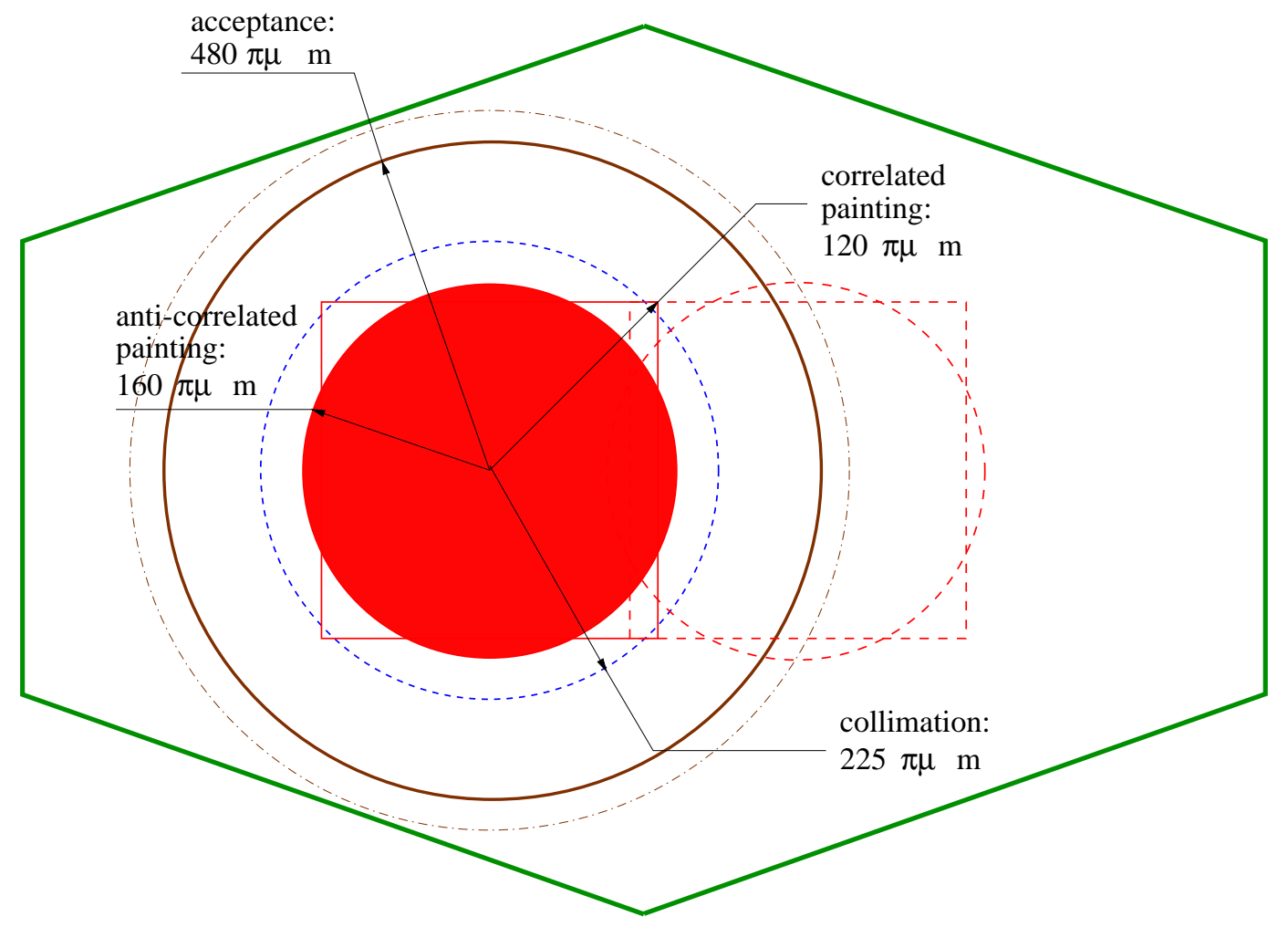

Figure 8: Schematic illustration of the beam emittance, collimation admittance, and vacuum chamber acceptance of the proposed hybrid lattice SNS ring. The green hexagonal box indicates the vacuum chamber cross section $(23 \mathrm{~cm}$ width, $15.2 \mathrm{~cm}$ height). The red squares correspond to off-momentum at $\Delta p / p$ of $\pm 1 \%$. The ring magnet acceptance for the entire beam is $480 \pi \mathrm{mm} \cdot \mathrm{mr}$, the total transverse emittance is either $160 \pi \mathrm{mm} \cdot \mathrm{mr}$ for anti-correlated and coupled painting or up to $240 \pi \mathrm{mm} \cdot \mathrm{mr}$ for correlated painting. Ring collimation is planned at either 225 or $240 \pi \mathrm{mm} \cdot \mathrm{mr}$. 
coupled (correlated) painting method, the final beam distribution on the mercury target is elliptical in the transverse plane. The total transverse emittance is $160-240 \pi \mathrm{mm} \cdot \mathrm{mr}$ resulting in a space-charge tune shift of about 0.15 .

The two-stage collimation is performed at an acceptance from about 225 to $275 \pi \mathrm{mm} \cdot \mathrm{mr}$. The estimated beam tail at $225 \pi \mathrm{mm} \cdot \mathrm{mr}$ is about $2 \times 10^{-3}$, and the collimation efficiency is about $95 \%$. Thus, the total uncontrolled beam loss is about $10^{-4}$. Alternatively, with correlated painting method the final beam distribution on the mercury target is rectangular in the transverse plane. The beam is painted with both the horizontal and vertical emittance of up to $120 \pi \mathrm{mm} \cdot \mathrm{mr}$ (total $240 \pi \mathrm{mm} \cdot \mathrm{mr}$ ). The two-stage collimation is performed at an acceptance from about $240 \pi \mathrm{mm} \cdot \mathrm{mr}$. Although beam is susceptible to transverse coupling induced by space-charge force and quadrupole roll misalignment, the coupling is greatly reduced when the tunes are split by more than a half units.

As shown in Table 3, the full momentum momentum spread is $\pm 0.7 \%$. The momentum acceptance provided by the RF system of $40 \mathrm{kV}$ voltage (harmonic $h=1$ ) is $\pm 1 \%$. The physical aperture of the machine allows a momentum acceptance of more than $\pm 2 \%$ for a beam of 160 $\pi \mathrm{mm} \cdot \mathrm{mr}$ unnormalized emittance. In order to reach this value, chromatic sextupoles need to be activated to correct off-momentum optical mismatch.

Table 3: Momentum aperture and sextupole improvement.

\begin{tabular}{lr}
\hline Item & Value \\
\hline Beam momentum spread $(99 \%)$ & \pm 0.007 \\
RF acceptance at $40 \mathrm{kV}(\mathrm{h}=1)$ & \pm 0.010 \\
Ring acceptance at nominal emittance & \pm 0.015 \\
Ring acceptance with sextupole correction & \pm 0.020 \\
\hline
\end{tabular}

\subsubsection{Lattice and working points}

The working points remain the same as the original hybrid lattice. At the nominal working point, the arc and the straight section lattice $\beta$ function is matched, ensuring lowest possible $\beta$ function in the arc for given cell length. The horizontal betatron phase advance is 360 degrees across each arc section so that the dispersion function is zero in all the straight sections. Comparing with that of the original hybrid lattice, the $\beta_{\max }$ to $\beta_{\min }$ ratio of the proposed lattice is increased from about 7.5 to 10.7 .

The FODO arc structure is flexible for both chromatic correction and resonance corrections, while the long straight sections are flexible for injection and collimation. There is one power supply for the arc dipoles, and five power supplies for the lattice quadrupoles. Chromatic sextupoles are planned to be powered by four families of power supplies for nonlinear chromatic adjustments.

The FODO-doublet hybrid structure is flexible in tune adjustment for about 1 unit in both the horizontal and vertical directions. The alternative working points are $(6.30,5.27),(5.82$, $4.80)$ and $(5.82,5.80)$. Figures 9 shows the lattice functions for one super-period of the ring for the nominal working point. Table 4 compares the advantage and disadvantage of these 


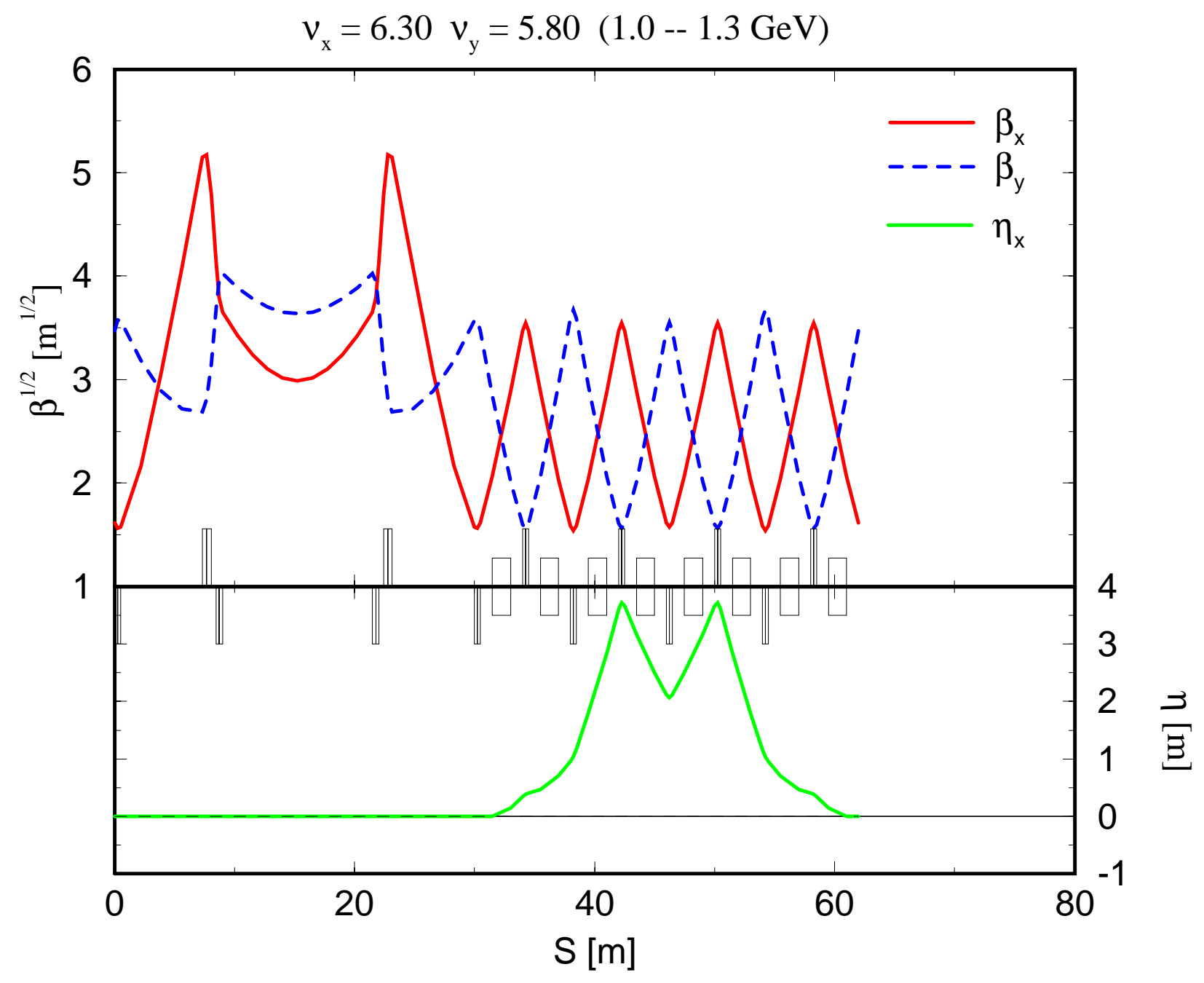

Time: Sun Dec 19 18:38:10 1999 Last file modify time: Fri Dec 17 13:56:46 1999

Figure 9: Lattice functions at tunes $\left(Q_{x}, Q_{y}\right)$ of $(6.30,5.80)$ for one super-period of the proposed $1.3 \mathrm{GeV}$-compatible SNS ring. 
working points. Potential structure resonances are corrected by magnetic corrector packages (skew quadrupole, normal and skew sextupole, and octupole).

Table 4: Comparison of tune working points for the hybrid lattice.

\begin{tabular}{llll}
\hline$\left(Q_{x}, Q_{y}\right)$ & Advantage & Disadvantage & Correction \\
\hline$(6.30,5.80)$ & perfect matching & near $2 Q_{x}+2 Q_{y}=24$ & octupole \\
& split tune & space charge) & \\
& ISIS operation & near $2 Q_{x}=12$ & \\
& high tunes & near $3 Q_{y}=16$ & skew sextupole \\
& near $2 Q_{y}-Q_{x}=4$ & sextupole \\
& (sextupole) & \\
& nplit tune & near $2 Q_{x}=12$ & \\
& CERN operation & large $\beta_{\max } / \beta_{\min }$ & \\
& & coupling (square beam) & skew quadrupole \\
\hline$(5.30,5.27,5.80)$ & coupled painting & loss-heavy for CERN & \\
& away from integer & AGS / Booster operation & \\
& & large $\beta_{\max } / \beta_{\min }$ & \\
& near $2 Q_{y}-Q_{x}=4$ & facing away \\
& loss-heavy for CERN & sextupole \\
\hline$(5.82,4.80)$ & awlit tune & & \\
& AGS from integer & & \\
\hline
\end{tabular}

\subsubsection{Injection and painting options}

Longitudinally, the momentum fluctuation of the beam is compensated by the energy corrector cavity in the HEBT line, while the momentum spread of the beam is broadened by the energy "wobbler" cavity in the HEBT line. Figure 10 shows the longitudinal distribution of the beam in the ring at the end of injection.

Transversely, desired beam distribution is achieved by injection painting. With the long straight section provided by the doublets, beam injection is essentially decoupled from lattice tuning. As shown in Figures 11 and 12, the fixed injection chicane is located between two nearby doublet quadrupole pairs. Figure 13 shows the two of the three painting schemes proposed for beam injection. Extra (50\% beam size) vertical clearance is reserved in the injection section to accommodate anti-correlated orbit bumps for painting. Table 5 compares the expected performance of correlated, anti-correlated, and coupled-correlated painting schemes for beam injection. Programmable kickers are planned for the flexibility of dynamic orbit bumps for injection painting.

The stripper foil sits in a dipole magnetic field of $2.5 \mathrm{kG}$. As a consequence, stripped electrons will rotate about the magnetic field lines in a tight circle of radius $\rho=1.23 \mathrm{~cm}$. To sweep these stripped electrons out of the ring without hitting (and further damaging) the foil, we take advantage of the fact that the foil sits in the downstream fringe field of its magnet: The electrons' center of gyration will travel downwards along a magnetic field line at a speed $\beta c \sin \alpha$, where $\alpha$ denotes the angle between the field line and the vertical at the 


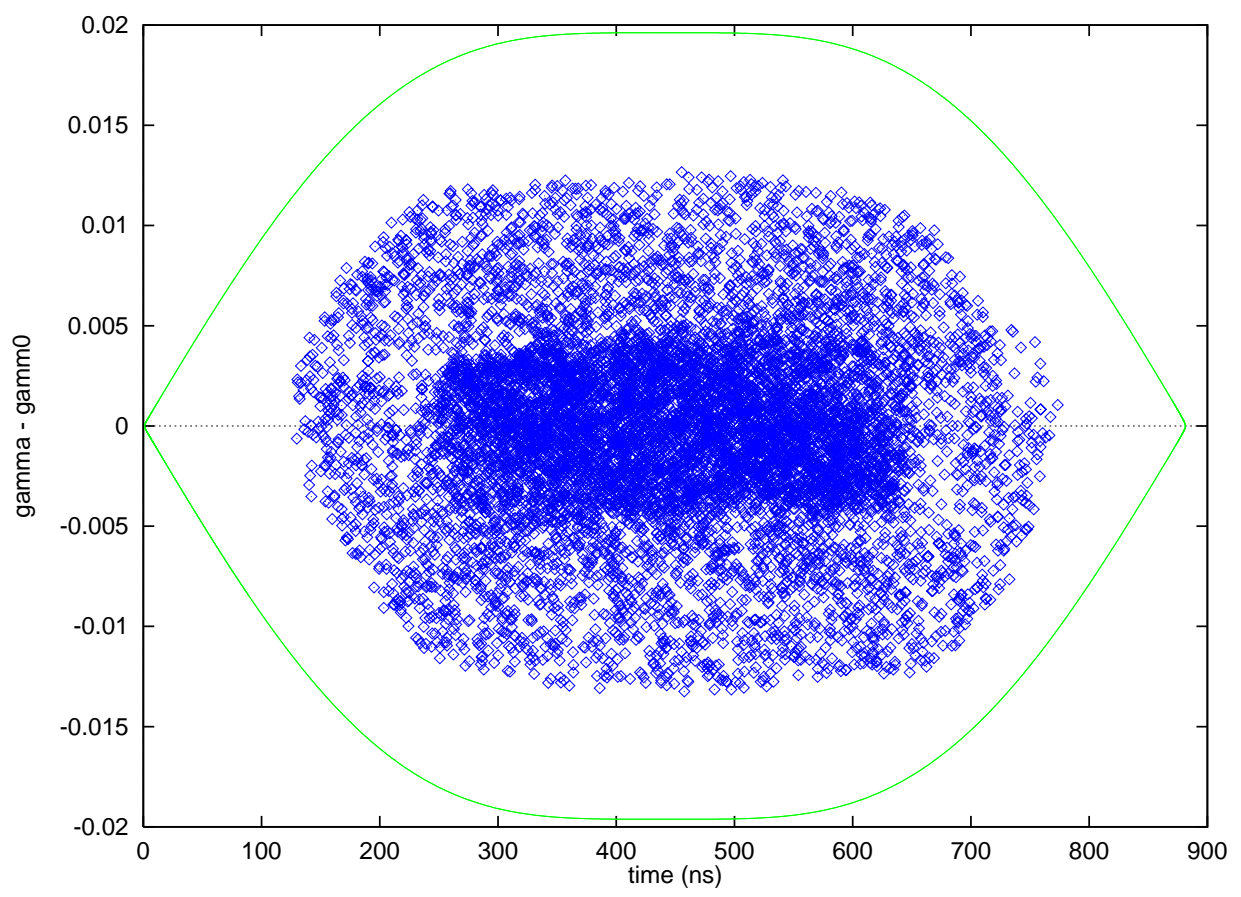

Figure 10: Longitudinal phase space distribution of the beam at the end of injection.

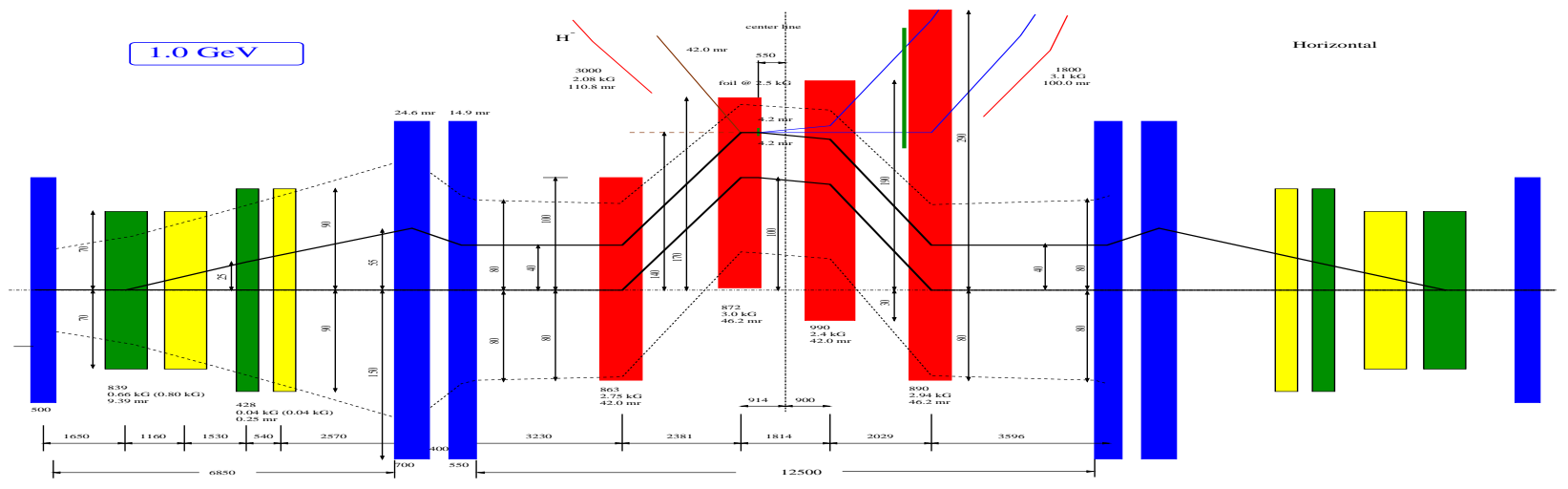

Figure 11: Horizontal schematic layout of the beam injection region of the proposed $1.3 \mathrm{GeV}$ compatible ring operating at $1 \mathrm{GeV}$. 


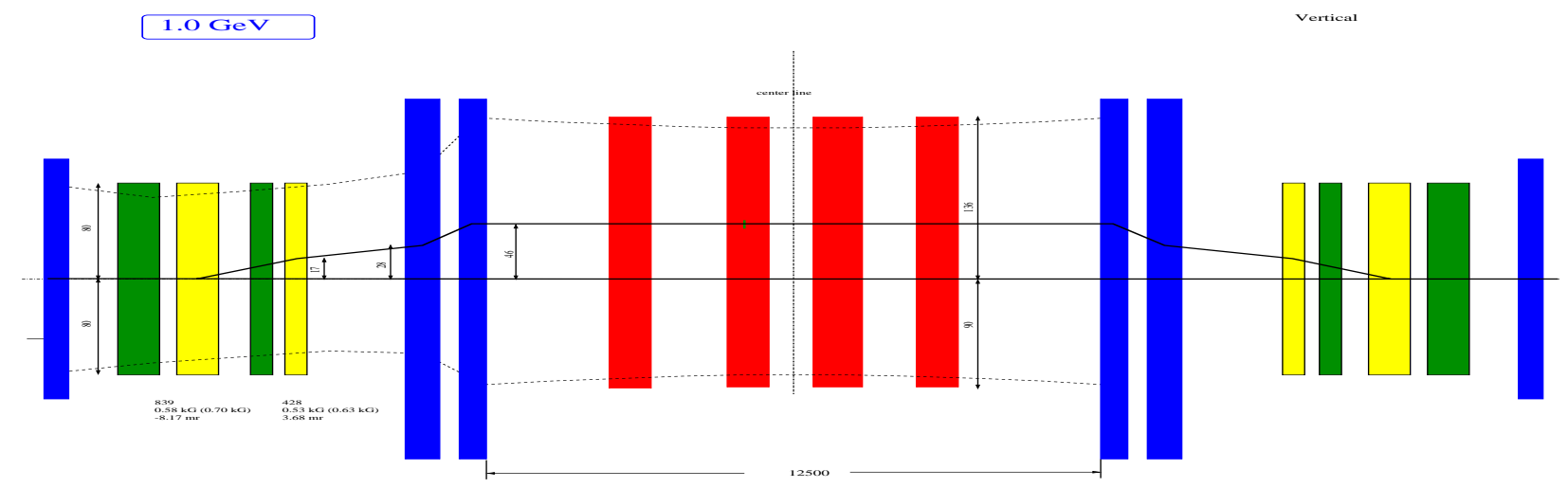

Figure 12: Vertical schematic layout of the beam injection region of the proposed $1.3 \mathrm{GeV}$ compatible ring operating at $1 \mathrm{GeV}$.

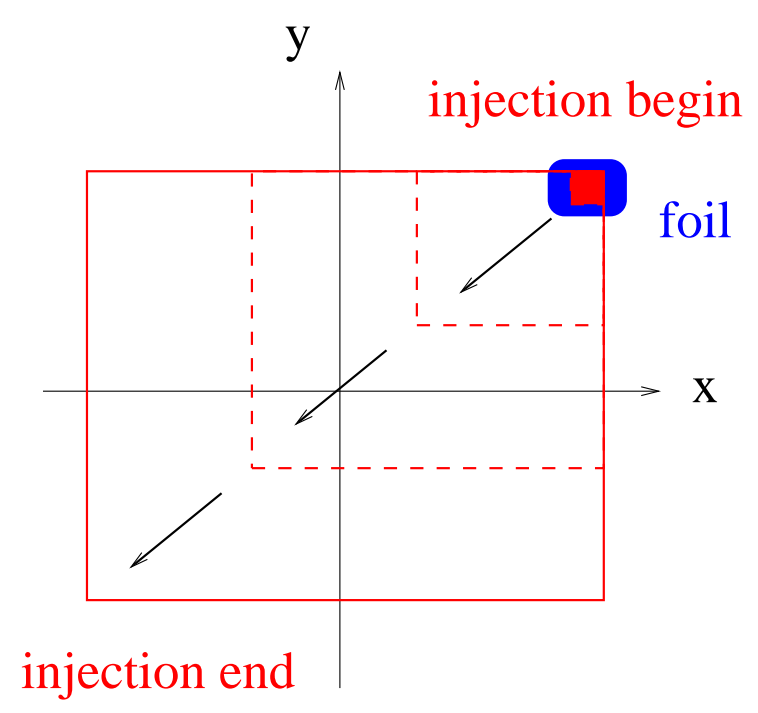

(a)

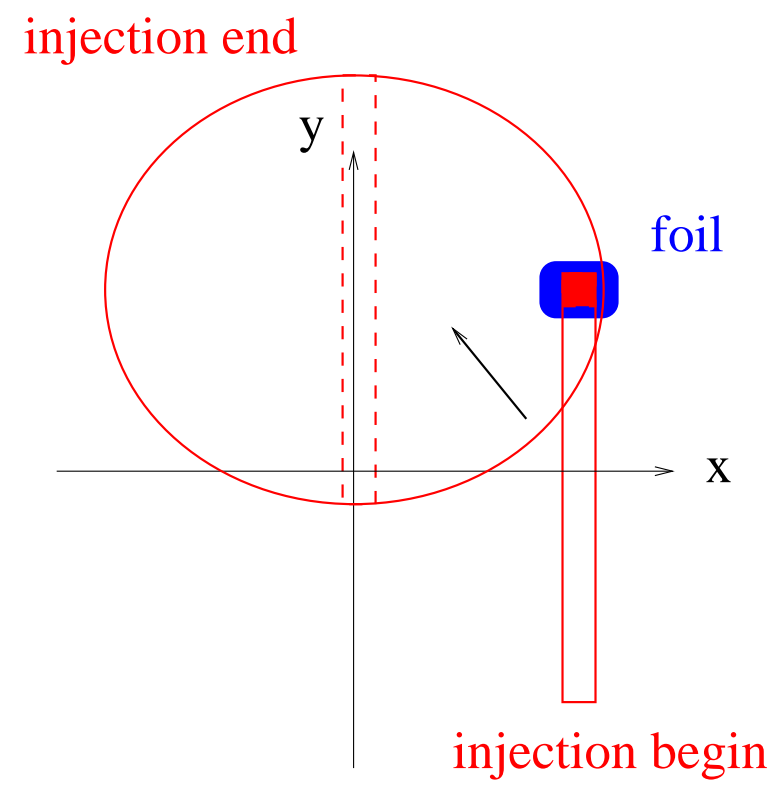

(b)

Figure 13: Correlated and anti-correlated painting injection schemes. 
point of injection. To ensure that the stripped electrons clear the lower edge of the foil on their first return, the injection C-magnet is designed so that $\alpha \geq 0.65 \mathrm{mr}$. And to prevent the electrons being reflected back upwards by an effective mirror field, the lower pole face will not be chamfered. A grounded and water-cooled block of copper will catch the electrons.

Extra space is reserved for the replacement of the two dipoles located near the center of the injection. When the machine is upgraded for $1.3 \mathrm{GeV}$ operation, these two dipoles will be replaced by longer magnets operating at lower fields.

\subsubsection{Collimation and loss distribution}

Immediately following the injection section is the multi-stage beam collimation section. This section consists of movable primary scatterers and three self-shielded collimators located in three consecutive drift spaces. Figure 14 shows expected collimation efficiency as a function of the available ring acceptance [7]. At a design acceptance of $480 \pi \mathrm{mm} \cdot \mathrm{mr}$, the expected collimation efficiency is about $95 \%$. Figure 15 shows the expected distribution of controlled and uncontrolled beam loss at various locations of the HEBT, ring, and RTBT assuming $2 \times 10^{-3}$ beam halo $[8,10,11,12]$ collected by the primary scatterer. Major uncontrolled beam loss is expected to be at the injection region caused by nuclear scattering of the foil, and from inefficiency of the collimation system. Beam residual in the gap between subsequent Linac bunches is cleaned by the beam-in-gap (BIG) kicker together with the multi-stage collimation system $[14,15]$.

\subsubsection{Extraction}

The accumulated beam in the SNS ring will form a single bunch $\sim 645$ ns long, with a gap of about $250 \mathrm{~ns}$. Extraction of the accumulated beam will happen soon after the injection process is completed (few hundred revolutions). and the beam will be extracted from the accumulator ring in a single beam revolution, and will last $\sim 945 \mathrm{~ns}$. The maximum extraction rate will be $60 \mathrm{~Hz}$. The selected extraction scheme is to use a two-step process consisting of, first "kicking" the beam with fast kickers into a Lambertson type septum magnet and second, deflect the beam using the septum magnet into the extraction beam line (RTBT). The extraction system will consist of 14 fast kickers ( $\tau$-200 ns) and a single Lambertson type septum magnet. The extraction will take place in one of the straight sections of the accumulator ring, with 7 kickers placed upstream of the quadrupole doublet and 7 kickers placed downstream of the doublet (Figure 16) followed by the septum magnet. During the gap of the beam $(\tau \sim 250 \mathrm{~ns})$, the kickers will rise to their full strength required for extraction, and will remain on for $\sim 695 \mathrm{~ns}$ until the beam is extracted from the accumulator ring into the Lambertson septum magnet. The kickers will deflect the beam vertically, and the Lambertson septum will deflect the beam horizontally in order to clear the quadrupole following the septum. The requirements for the extraction system are summarized in Table 6 .

The kickers are made of ferrite core with rectangular cross-section (window frame). A single-turn copper conductor is center-fed by one of the sides of the ferrite core. The length and the cross section of the ferrite of each kicker have been chosen in order to fulfill two requirements. First to reduce the maximum voltage and current which will power the kickers 
Table 5: Comparison of injection schemes for the hybrid lattice.

\begin{tabular}{lcll}
\hline Scheme & $\begin{array}{c}\epsilon_{x}+\epsilon_{y} \\
{[\pi \mathrm{mm} \cdot \mathrm{mr}]}\end{array}$ & Advantage & Disadvantage \\
\hline Correlated & $120+120$ & $\begin{array}{l}\text { square shaped beam } \\
\text { painting over halo }\end{array}$ & susceptible to coupling growth \\
\hline Anti-correlated & 160 & $\begin{array}{l}\text { round shaped beam } \\
\text { K-V like distribution } \\
\text { immune to coupling }\end{array}$ & $\begin{array}{l}\text { extra } 50 \% \mathrm{~V} \text { aperture } \\
\text { halo not painted over }\end{array}$ \\
\hline Coupled H-V & $80+80$ & $\begin{array}{l}\text { painting over halo } \\
\text { immune to coupling }\end{array}$ & $\begin{array}{l}\text { requiring full coupling } \\
\text { (unsplit tune / skew quad) }\end{array}$ \\
\hline
\end{tabular}

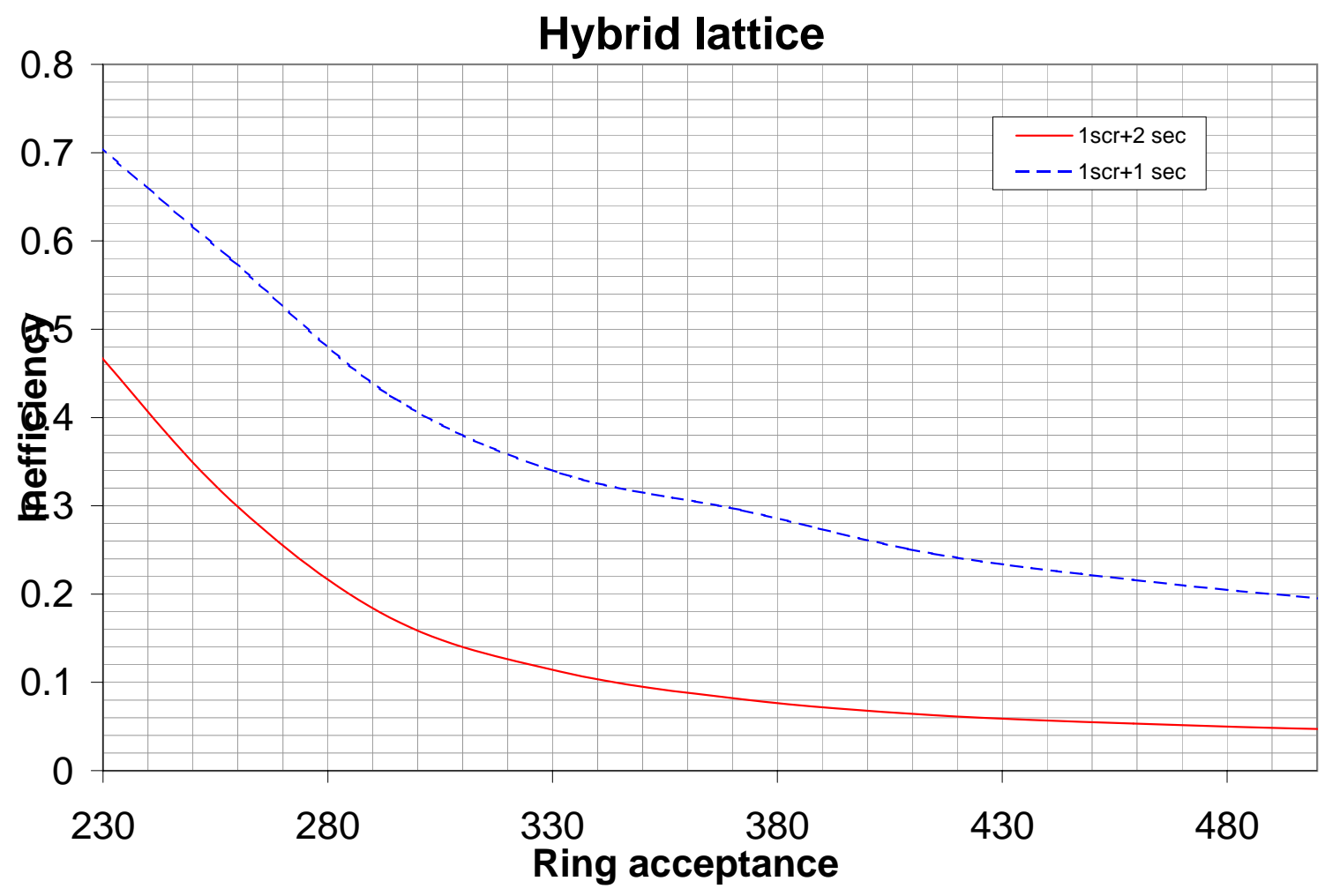

Figure 14: Comparison of collimation efficiency of the proposed SNS ring with one or two secondary collimators in addition to the primary scraper. With two secondary collimators, the efficiency corresponding to the proposed acceptance of $480 \pi \mathrm{mm} \cdot \mathrm{mr}$ is about $95 \%$. 


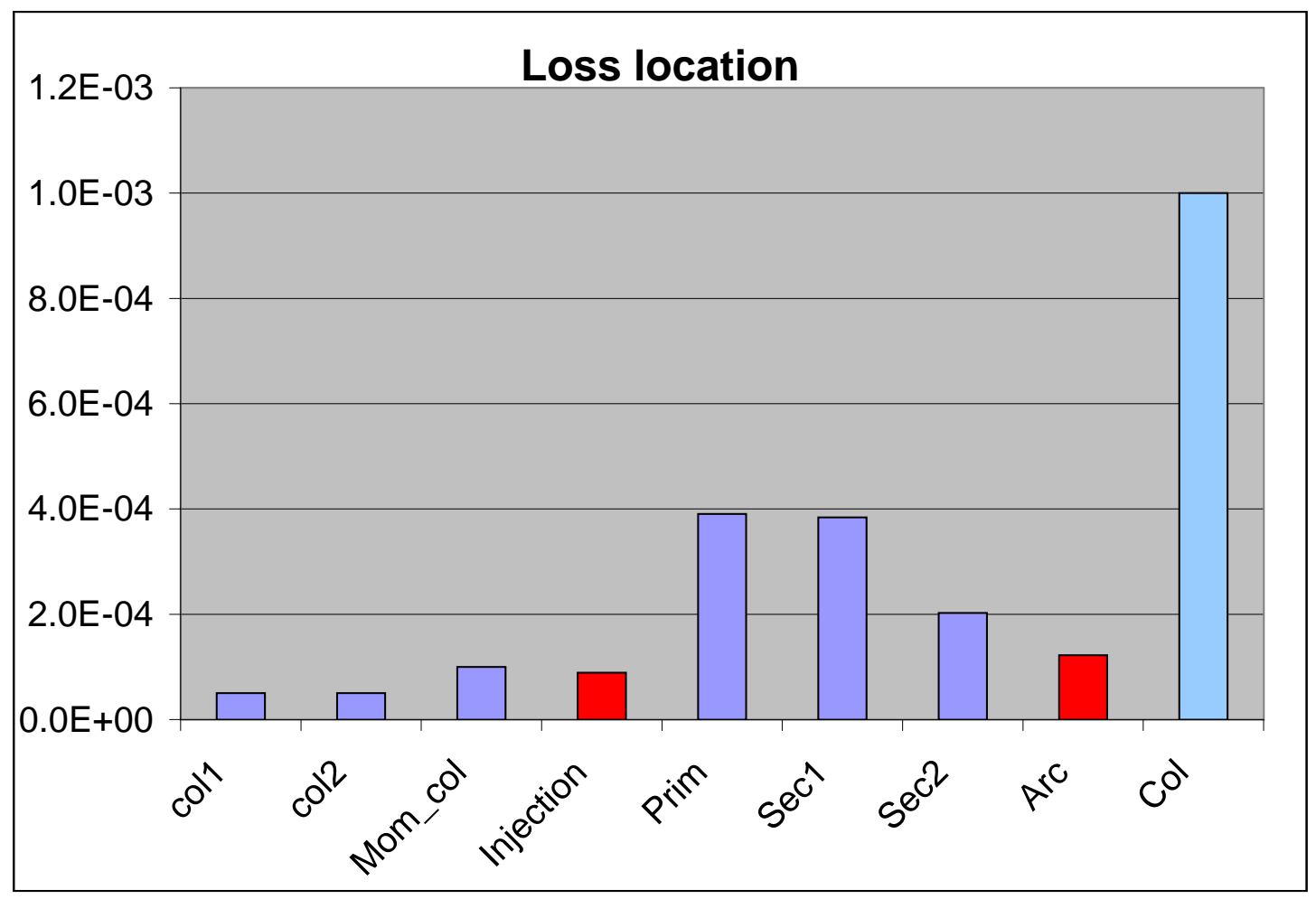

Figure 15: Expected controlled (purple), uncontrolled (red), and accidental (blue) beam loss at various locations of High-Energy-Beam-Transfer (HEBT) line, Ring, and Ring-to-TargetBeam-Transfer (RTBT) line.

Table 6: Extraction magnet parameters for the proposed hybrid lattice SNS ring.

\begin{tabular}{lll}
\hline Parameter & Base Value & Comment \\
\hline Extraction type & single-turn & two-step \\
Beam extraction gap & $250 \mathrm{~ns}$ & \\
Maximum extraction rate & $60 \mathrm{~Hz}$ & \\
First step: & 14 kickers & full aperture \\
Kick strength & 1.16 to $1.65 \mathrm{mr}$ & vertical \\
Kicker rise-time & $200 \mathrm{~ns}$ & 0 to $97 \%$ \\
Second step: & Lambertson septum & \\
Lambertson deflection & $16.8^{\circ}$ & horizontal \\
Single kicker failure & beam on target & \\
\hline
\end{tabular}


to level where the components can operate reliably, without the use of special insulation materials like oil. Second to allow the full beam to be extracted within the acceptance of the RTBT line and transported to target even with one of the kickers missing. The cross section of the fast kickers have been chosen in order to provide an acceptance of $480 \pi \mathrm{mm} \cdot \mathrm{mr}$ during the injection/accumulation period and an acceptance of $400 \pi \mathrm{mm} \cdot \mathrm{mr}$ during the extraction. The same extraction acceptance of $400 \pi \mathrm{mm} \cdot \mathrm{mr}$ applies also for the doublet quadrupoles between the kicker modules. The maximum vertical deflection of the central orbit of the beam at the entrance of the Lambertson is $168 \mathrm{~mm}$. This deflection corresponds to an acceptance of 400 $\pi \mathrm{mm} \cdot \mathrm{mr}$ at the entrance of the septum.

The Lambertson septum magnet is used to deflect horizontally by $16.8^{\circ}$, the fast beam from the accumulator ring. This beam deflection is adequate for the beam to clear the quadrupole downstream of the septum. The Lambertson magnet, running in a dc mode, is designed to minimize the field (few Gauss) in the circulating beam region.

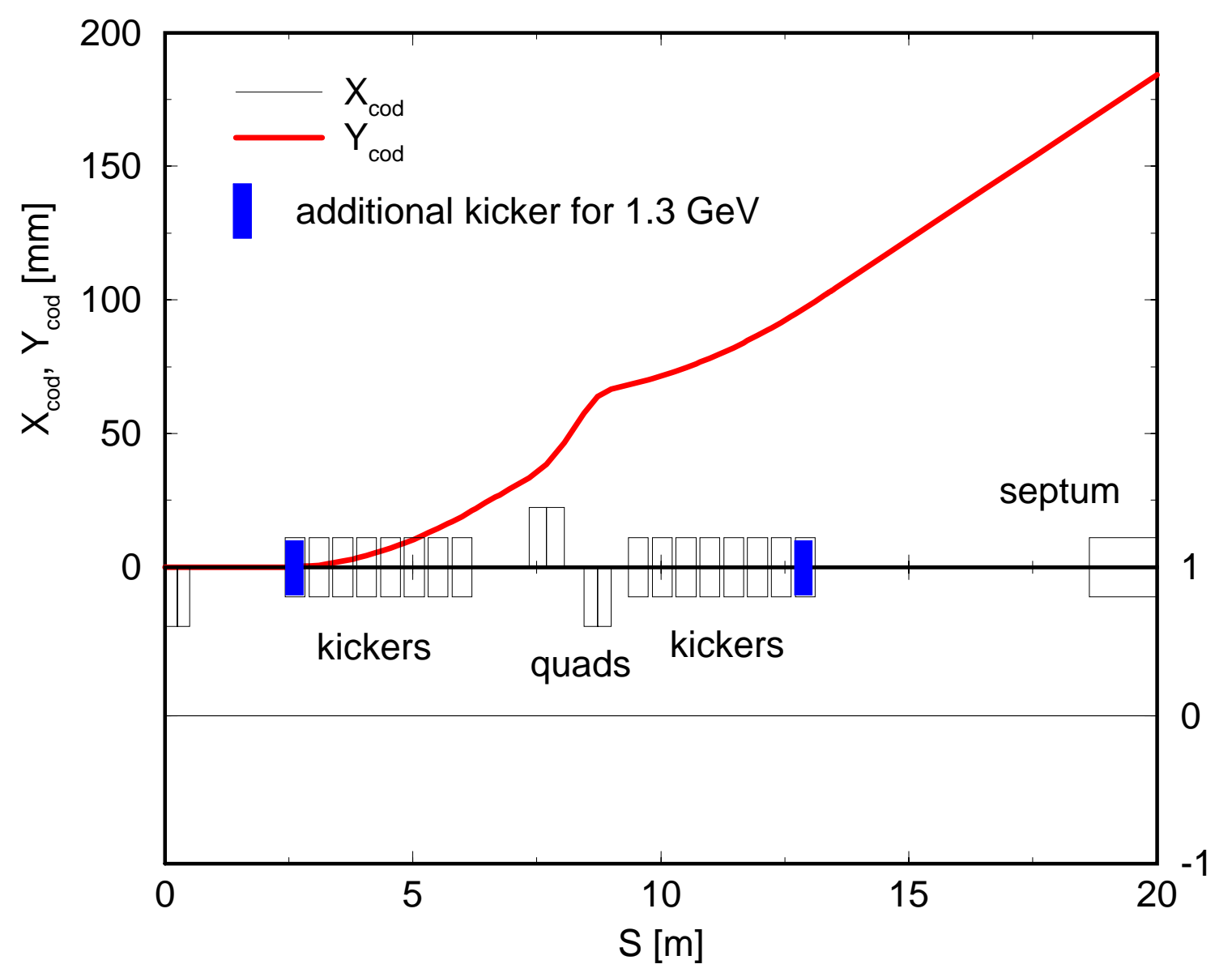

Figure 16: Extraction layout and closed orbit of the $1.3 \mathrm{GeV}$-compatible ring. The two kickers marked with blue color are reserved for $1.3 \mathrm{GeV}$ operation. 
Space is reserved for the addition of two extra kickers for $1.3 \mathrm{GeV}$ operation without changing the location of the existing 14 kickers.

\subsubsection{Magnets}

Mechanically, all magnets except the two injection dipoles are designed to operate up to 1.3 $\mathrm{GeV}$ without field saturation and deterioration. Electrically, the magnet power supplies are designed only for $1 \mathrm{GeV}$ operation.

Table 7 lists major parameters of the arc section dipole magnet. Table 8 lists the major

Table 7: Dipole magnet parameters for the proposed hybrid lattice SNS ring.

\begin{tabular}{lll}
\hline Quantity & Value & unit \\
\hline Dipole: & & \\
bend angle & 11.25 & degree \\
number & $32+1$ & used + reference \\
magnetic length & 1.4 & $\mathrm{~m}$ \\
sagitta & 3.85 & $\mathrm{~cm}$ \\
pole width & 45 & $\mathrm{~cm}$ \\
gap height & 17 & $\mathrm{~cm}$ \\
magnetic field & $0.792-0.950$ & $\mathrm{~T}$ \\
\hline
\end{tabular}

parameters of the ring quadrupoles. The quadrupoles at the end of the 12.5-meter straight section drift space are designed to be of "figure of 8 " to accommodate the clearance requirements of injection and extraction layout. The strength of the quadrupoles include a $10 \%$ margin that is adequate for the tuning of the lattice working point. Table 9 lists the major parameters of the chromatic sextupole magnets.

Major parameters for the injection magnets are listed in Table 10. The $3 \mathrm{kG}$ field of the magnets INJSEPTM1 and INJBND2 is chosen to reduce pre-foil stripping of $\mathrm{H}^{-}$ions to a level below $10^{-6}$ per meter, while the $2.4 \mathrm{kG}$ field of the magnet INJBND3 is chosen to minimize the stripping of $n=4$ and lower quantum state $\mathrm{H}^{0}$ ions before the second stripping foil. The foil is located at a field of $2.5 \mathrm{kG}$. The beam is injected with zero transverse momenta at the foil. The dynamic bump injection dipoles are places symmetrically in each 6.85-meter drift spaces. The power supply waveform of the dynamic bump magnets is designed to be programmable for the flexibility of manipulating the transverse beam profile to achieve the desired distribution required by the target. Table 11 lists main parameters of the dynamic bump kickers.

Tables 12 and 13 summarize the specification of the extraction kickers and septum magnet. The acceptance of the extraction channel is $400 \pi \mathrm{mm} \cdot \mathrm{mr}$, and the acceptance of the downstream RTBT line is $480 \pi \mathrm{mm} \cdot \mathrm{mr}$. The expected beam loss at the extraction region is below $10^{-6}$. 
Table 8: Quadrupole magnet parameters for the proposed hybrid lattice SNS ring.

\begin{tabular}{lll}
\hline Quantity & Value & unit \\
\hline Quadrupole: & & \\
Regular ring quadrupole: & & \\
number & 28 & used \\
magnetic length & 0.5 & $\mathrm{~m}$ \\
magnetic strength, $B^{\prime} / B \rho$ & 0.82 & $\mathrm{~m}^{-2}$ \\
magnetic gradient & $4.7-5.6$ & $\mathrm{~T} / \mathrm{m}$ \\
pole inscribed diameter & 21 & $\mathrm{~cm}$ \\
peak field at pole tip & $0.49-0.59$ & $\mathrm{~T}$ \\
& & \\
Large ring arc quadrupole: & & \\
number & 8 & $\mathrm{used}$ \\
magnetic length & 0.5 & $\mathrm{~m}$ \\
magnetic strength, $B^{\prime} / B \rho$ & 0.82 & $\mathrm{~m}^{-2}$ \\
magnetic gradient & $4.7-5.6$ & $\mathrm{~T} / \mathrm{m}$ \\
pole inscribed diameter & 26 & $\mathrm{~cm}$ \\
peak field at pole tip & $0.61-0.73$ & $\mathrm{~T}$ \\
& & \\
Long ring straight quadrupole: & & \\
number & 8 & $\mathrm{used}$ \\
magnetic length & 0.7 & $\mathrm{~m}$ \\
magnetic strength, $B^{\prime} / B \rho$ & 0.77 & $\mathrm{~m}$ \\
magnetic gradient & $4.3-5.2$ & $\mathrm{~T} / \mathrm{m}$ \\
pole inscribed diameter & 30 & $\mathrm{~cm}$ \\
peak field at pole tip & $0.65-0.78$ & $\mathrm{~T}$ \\
& & \\
Narrow ring straight quadrupole: & & \\
number & 8 & $\mathrm{used}$ \\
magnetic length & 0.55 & $\mathrm{~m}$ \\
magnetic strength, $B^{\prime} / B \rho$ & 0.77 & $\mathrm{~m}^{-2}$ \\
magnetic gradient & $4.3-5.2$ & $\mathrm{~T} / \mathrm{m}$ \\
pole inscribed diameter & 30 & $\mathrm{~cm}$ \\
peak field at pole tip & $0.65-0.78$ & $\mathrm{~T}$ \\
& & \\
\hline & & \\
\hline
\end{tabular}


Table 9: Sextupole magnet parameters for the proposed hybrid lattice SNS ring.

\begin{tabular}{lll}
\hline Quantity & Value & unit \\
\hline $\begin{array}{l}\text { Sextupole: } \\
\text { Regular ring sextupole: }\end{array}$ & & \\
number & 12 & \\
magnetic length & 0.15 & $\mathrm{~m}$ \\
magnetic strength, $B^{\prime \prime} / B \rho$ & 8.3 & $\mathrm{~m}^{-3}$ \\
magnetic gradient & $47-57$ & $\mathrm{~T} / \mathrm{m}^{2}$ \\
pole inscribed diameter & 21 & $\mathrm{~cm}$ \\
peak field at pole tip & $0.26-0.31$ & $\mathrm{~T}$ \\
Large ring sextupole: & & \\
number & 8 & \\
magnetic length & 0.15 & $\mathrm{~m}$ \\
magnetic strength, $B^{\prime \prime} / B \rho$ & 8.3 & $\mathrm{~m}^{-3}$ \\
magnetic gradient & $47-57$ & $\mathrm{~T} / \mathrm{m}^{2}$ \\
pole inscribed diameter & 26.4 & $\mathrm{~cm}$ \\
peak field at pole tip & $0.41-0.49$ & $\mathrm{~T}$ \\
\hline
\end{tabular}

Table 10: Injection DC magnet parameters for the proposed $1.3 \mathrm{GeV}$-compatible SNS ring operating at $1 \mathrm{GeV}$.

\begin{tabular}{lcccccc}
\hline Quantity & INJSEPTM1 & INJBND1 & INJBND2 & INJBND3 & INJBND4 & INJSEPTM2 \\
\hline Kick [mr] & 110.8 & 42.0 & 46.2 & 42.0 & $46.2-47.3$ & 174.5 \\
Gap (V)[cm] & 6.9 & 23.8 & 23.5 & 23.5 & 23.5 & 6.0 \\
Effective & 306.9 & 87.5 & 87.4 & 99.0 & 90.5 & 220.0 \\
length [cm] & & & & & & \\
Mechanical & 300.0 & 63.7 & 63.9 & 75.5 & 67.0 & 213.0 \\
length [cm] & & & & & & \\
No. of turns & 4 & 14 & 28 & 28 & 28 & 8 \\
$B$ [kG] & $2.03-2.44$ & $2.72-3.26$ & 3.0 & 2.4 & $2.89-3.54$ & $4.5-5.4$ \\
$I_{\text {max }}[\mathrm{kA}]$ & 3.42 & 4.48 & 2.00 & 1.60 & 2.40 & 3.4 \\
Mag. res. [m $\Omega]$ & 0.87 & 1.25 & 3.61 & 4.04 & 2.84 & 1.38 \\
\hline
\end{tabular}


Table 11: Injection dynamic bump kicker parameters for the hybrid lattice.

\begin{tabular}{lll}
\hline Parameter & Long module & Short module \\
\hline Number & 4 & 4 \\
Kick [mr] & $9.39,8.17$ & $0.25,3.68$ \\
Maximum field [kG] & 0.79 & 0.62 \\
Core length [m] & 0.64 & 0.21 \\
Effective length [m] & 0.839 & 0.428 \\
Gap $(\mathrm{H} \times \mathrm{V})[\mathrm{cm}]$ & $22.5 \times 19.6$ & $24.5 \times 21.6$ \\
Maximum current $[\mathrm{A}]$ & 1230 & 1090 \\
Turns per coil & 10 & 10 \\
Inductance $[\mathrm{mH}]$ & 158 & 103 \\
Integral field deviation & 1.0 & 0.8 \\
Coil resistance $[\mathrm{m} \Omega]$ & 3.02 & 2.20 \\
\hline
\end{tabular}

Table 12: Extraction kicker parameters for the proposed hybrid lattice SNS ring.

\begin{tabular}{lcc}
\hline No. of kicker modules & 14 & \\
Effective length & 0.4 & $\mathrm{~m}$ \\
Kicker strength & $1.16-1.65$ & $\mathrm{mr}$ \\
Vertical displ. at septum entrance & 168 & $\mathrm{~mm}$ \\
Maximum kicker voltage & 34.5 & $\mathrm{kV}$ \\
Maximum kicker current & 3.0 & $\mathrm{kA}$ \\
\hline
\end{tabular}

Table 13: Extraction Lambertson magnet parameters for the proposed hybrid lattice SNS ring.

\begin{tabular}{lcc}
\hline Core length & 2.1 & $\mathrm{~m}$ \\
Bending angle & $16.8^{\circ}$ & $\mathrm{m}$ \\
Field & 8 & $\mathrm{kG}$ \\
Gap (V) & 14 & $\mathrm{~cm}$ \\
Width $(\mathrm{H})$ & 30 & $\mathrm{~cm}$ \\
Septum thickness & 1 & $\mathrm{~cm}$ \\
No. of turns & 60 & \\
Maximum current & 1500 & $\mathrm{~A}$ \\
Maximum $V_{d c}$ & 25 & $\mathrm{~V}$ \\
Coil resistance & 0.0135 & $\Omega$ \\
\hline
\end{tabular}




\subsubsection{Expected magnetic errors and misalignments}

Tables 14 and 15 list the expected integral magnetic errors of the ring dipole and quadrupole. The multipoles for the dipole magnet are extracted from the calculation of the design geometry. The multipoles for the quadrupole magnet are extracted and scaled from the measurement data of the AGS Booster magnets. Table 16 shows the expected misalignment based on the survey data of AGS Booster and the AGS-to-RHIC transfer line. Tables 17 and 18 show the contribution of dipole and quadrupole ends based on 3D field calculation.

Table 14: Expected magnetic errors of ring dipoles. The multipoles are normalized to $10^{-4}$ of the main field at the reference radius $\left(R_{r e f}\right)$ of $13 \mathrm{~cm}$.

\begin{tabular}{lcccc}
\hline$n$ & \multicolumn{2}{c}{ Normal } & \multicolumn{2}{c}{ Skew } \\
& $\left\langle b_{n}\right\rangle$ & $\sigma\left(b_{n}\right)$ & $\left\langle a_{n}\right\rangle$ & $\sigma\left(a_{n}\right)$ \\
\hline Body & {$[$ unit] } & & & \\
2 & -0.2 & 0.0 & 0.0 & 0.0 \\
4 & 0.8 & 0.0 & 0.0 & 0.0 \\
6 & -0.8 & 0.0 & 0.0 & 0.0 \\
8 & -3.0 & 0.0 & 0.0 & 0.0 \\
10 & -4.4 & 0.0 & 0.0 & 0.0 \\
12 & -2.4 & 0.0 & 0.0 & 0.0 \\
\hline
\end{tabular}

\subsubsection{Dynamic aperture}

Dynamic aperture analysis for the proposed ring is not yet completed. However, based on the analysis of the original lattice, it is expected that with the compensated field harmonics and corrected closed orbit, the dynamic aperture is near the physical aperture.

\subsubsection{Impedance and instabilities}

Impedance and instability analysis for the hybrid lattice is not yet completed. However, based on the scope of hardware change, changes on impedance budget and instability threshold are expected to be small $[16,17]$. 
Table 15: Expected magnetic errors of ring quadrupoles. The multipoles are normalized to $10^{-4}$ of the main field at the reference radius $R_{\text {ref }}$. For regular ring quadrupoles, $R_{\text {ref }}=10$ $\mathrm{cm}$; for large ring arc quadrupoles, $R_{\text {ref }}=12 \mathrm{~cm}$; for ring straight quadrupoles, $R_{\text {ref }}=14 \mathrm{~cm}$ (approximately $92 \%$ of the quadrupole iron pole tip radius).

\begin{tabular}{lrrrr}
\hline$n$ & \multicolumn{2}{c}{ Normal } & \multicolumn{2}{c}{ Skew } \\
& $\left\langle b_{n}\right\rangle$ & $\sigma\left(b_{n}\right)$ & $\left\langle a_{n}\right\rangle$ & $\sigma\left(a_{n}\right)$ \\
\hline Body & {$[$ unit $]$} & & & \\
2 & 0.0 & -2.46 & 0.0 & -2.5 \\
3 & 0.0 & -0.76 & 0.0 & -2.0 \\
4 & 0.0 & -0.63 & 0.0 & 1.29 \\
5 & 0.20 & 0.0 & 0.0 & 1.45 \\
6 & 0.0 & 0.02 & 0.0 & 0.25 \\
7 & 0.0 & -0.63 & 0.0 & 0.31 \\
8 & 0.0 & 0.17 & 0.0 & -0.11 \\
9 & 0.70 & 0.0 & 0.0 & 1.04 \\
10 & 0.0 & -0.06 & 0.0 & -0.05 \\
11 & 0.0 & -0.22 & 0.0 & -0.09 \\
12 & 0.0 & -0.06 & 0.0 & 0.08 \\
13 & -1.41 & 0.0 & 0.0 & 0.26 \\
Ends & {$[$ unit.m] } & & $($ Length $=0.15 \mathrm{~m})$ \\
6 & 0.25 & 0.0 & 0.0 & 0.0 \\
\hline
\end{tabular}

Table 16: Expected alignment errors of ring magnets based on the survey measurement of the AGS Booster magnets and the AGS-to-RHIC transfer line magnets.

\begin{tabular}{lr}
\hline Item & Value \\
\hline Integral field, magnet-to-magnet variation $^{a}(\mathrm{rms})$ & $10^{-4}$ \\
Integral field, transverse variation $^{c}$ within $R_{\text {ref }}(\mathrm{rms})$ & $10^{-4}$ \\
Ring dipole sagitta deviation & $3 \mathrm{~cm}$ \\
Magnetic center position $^{a, b}(\mathrm{rms})$ & $0.1-0.5 \mathrm{~mm}$ \\
Magnet longitudinal position $^{b}(\mathrm{rms})$ & $0.5 \mathrm{~mm}$ \\
Mean field roll angle $^{a, b}(\mathrm{rms})$ & $0.2-1 \mathrm{mr}$ \\
\hline
\end{tabular}


Table 17: Integrated dipole end field at one magnet end before pole tip end shimming, extracted from 3D TOSCA calculation. Normalized to $10^{-4}$ of the main field at the reference radius $R_{\text {ref }}=13 \mathrm{~cm}$. The measurement radius is $7 \mathrm{~cm}$.

\begin{tabular}{rrrrr}
\hline$n$ & \multicolumn{2}{c}{ Normal } & \multicolumn{2}{c}{ Skew } \\
& $\left\langle b_{n}\right\rangle$ & $\sigma\left(b_{n}\right)$ & $\left\langle a_{n}\right\rangle$ & $\sigma\left(a_{n}\right)$ \\
\hline 1 & 0.1 & - & 0.0 & - \\
2 & 51 & - & 0.0 & - \\
3 & 0.5 & - & 0.0 & - \\
4 & -26 & - & 0.0 & - \\
5 & 0.2 & - & 0.0 & - \\
\hline
\end{tabular}

Table 18: Integrated quadrupole end field from one magnet end before pole tip end shimming, extracted from 3D TOSCA calculation. Normalized to $10^{-4}$ of the main field at the reference radius $R_{\text {ref }}$. For regular ring quadrupoles, $R_{\text {ref }}=10 \mathrm{~cm}$; for large ring arc quadrupoles, $R_{\text {ref }}=12 \mathrm{~cm}$; for ring straight quadrupoles, $R_{\text {ref }}=14 \mathrm{~cm}$ (approximately $92 \%$ of the quadrupole iron pole tip radius).

\begin{tabular}{rrrrr}
\hline$n$ & \multicolumn{2}{c}{ Normal } & \multicolumn{2}{c}{ Skew } \\
& $\left\langle b_{n}\right\rangle$ & $\sigma\left(b_{n}\right)$ & $\left\langle a_{n}\right\rangle$ & $\sigma\left(a_{n}\right)$ \\
\hline 2 & 0.4 & - & 0.0 & - \\
3 & 0.1 & - & 0.0 & - \\
4 & 0.7 & - & 0.0 & - \\
5 & 121 & - & 0.0 & - \\
\hline
\end{tabular}




\subsection{Changes and Benefits}

The proposed ring is upgrade-able for $1.3 \mathrm{GeV}$ operation. Due to significantly increased ring straight length, injection and extraction arrangements become more relaxed. Consequently, the ring is expected to be easier for operational maintenance. Due to increased ring circumference and beam pulse length, less number of turns needs to be injected. Thus, foil hits is reduced by about $12 \%$, and foil lifetime is increased accordingly. Finally, with more free space available, the ring is more flexible for future upgrades.

Table 19 summarizes the major change of parameter of the ring, HEBT, and RTBT lines from the original hybrid lattice approved in October 1999 to the proposed $1.3 \mathrm{GeV}$-compatible design operating at $1 \mathrm{GeV}$ only. Further changes needed for $1.3 \mathrm{GeV}$ operation is listed in Section 6.

Table 19: Major change for the SNS ring between the original hybrid lattice (October 1999) and the proposed $1.3 \mathrm{GeV}$-compatible design operating at $1 \mathrm{GeV}$ only.

\begin{tabular}{llll}
\hline Quantity & Original & Proposed & Unit \\
\hline Circumference & 220.88 & 248.0 & $\mathrm{~m}$ \\
Maximum $\beta$ in straight & $19.7,13.6$ & $26.7,16.2$ & $\mathrm{~m}$ \\
Injection foil hit & 6 & $5-6$ & \\
Straight section space & $9.04,2 \times 5.45$ & $12.5,2 \times 6.85$ & $\mathrm{~m}$ \\
Ring quad. ID & 21,26 & $21,26,30$ & $\mathrm{~cm}$ \\
Ring quad. length & $0.5,0.6$ & $0.5,0.55,0.7$ & $\mathrm{~m}$ \\
Injection dipole length increase & - & 40 & $\%$ \\
Extraction Lambertson length increase & - & 15 & $\%$ \\
RF frequency $(h=1)$ & 1.187 & 1.058 & $\mathrm{MHz}$ \\
HEBT length & 137 & 162 & $\mathrm{~m}$ \\
Achromat dipole length increase & - & 40 & $\%$ \\
Proton pulse width on target & 590 & 695 & $\mathrm{~ns}$ \\
Proton momentum spread on target & \pm 0.70 & \pm 0.74 & $\%$ \\
\hline
\end{tabular}

\subsubsection{Lattice and layout}

The general configuration of HEBT, ring, and RTBT remain the same. The length of HEBT line is increased by $25 \mathrm{~m}$. The length of RTBT line is assumed to be the same, provided that the target can be relocated about $10 \mathrm{~m}$ from the original site towards the ring.

The ring circumference is increased by $27.12 \mathrm{~m}$, all resulted from the increase in straight length. With matching, the lattice function in the arc remain the same. The maximum $\beta$ function in the straights is increased from $19.7 \mathrm{~m}$ to $26.7 \mathrm{~m}$. The ring dispersion remains the same. The ratio between maximum and minimum $\beta$ is increased from about 7.5 to 10.7 across the entire ring. The lengths of straight section are increased from 9.04 and 5.45 to 12.5 and $6.85 \mathrm{~m}$, respectively. The working points remain the same. 


\subsubsection{Ring acceptance}

Due to corresponding increase of dimension of straight section magnets, the ring, HEBT, and RTBT acceptance is kept the same.

\subsubsection{Space-charge tune shift and beam tail}

Space-charge tune shift remains the same. Beam halo development is expected to be moderately increased due to the increase of beam envelope variation.

\subsubsection{Collimation efficiency and uncontrolled beam loss}

Collimation efficiency, as well as the amount and distribution of uncontrolled beam loss are expected to be similar.

\subsubsection{Ring magnets and power supplies}

The number of power supplies remains the same.

For the ring lattice dipole, the physical dimension (vertical $17 \mathrm{~cm}$ gap) and power supply specification remains the same. The amount of steel is increased by about $20 \%$ to avoid excessive saturation.

Instead of three types of quadrupoles, four types of quadrupoles, two for the arcs and two for the straights, are needed for the ring. For the arc quadrupoles, the dimension and power supply specification remain the same, but the number of coil turns is increased from 24 to 28 , and the amount of steel is also increased. For the straight quadrupoles, their inscribed diameters are increased from 26 to $30 \mathrm{~cm}$, and lengths increased from 0.5 to $0.55 \mathrm{~m}$, and from 0.6 to $0.7 \mathrm{~m}$, respectively. The power supply strength is increased accordingly.

\subsubsection{Injection and extraction}

The size of the fixed injection chicane is increased from 6 to $10 \mathrm{~cm}$. The correspondingly increased optical perturbation produced by the chicane is acceptable.

The number of injection chicane magnets and dynamic bump dipoles remain the same, but their length, strength, and transverse dimension are changed. Space is reserved for future replacement of two injection dipoles for $1.3 \mathrm{GeV}$ operation.

The number and strength of extraction kicker modules remains the same, but the dimension is increased. The length of extraction Lambertson septum is increased from 2.1 to $2.4 \mathrm{~m}$. Space is reserved for addition of two kicker modules for $1.3 \mathrm{GeV}$ operation.

\subsubsection{Vacuum chamber}

For the ring arcs, the vacuum chamber design remains the same. For the ring straights, the dimension of vacuum chamber is increased by up to about $20 \%$. 


\subsubsection{HEBT}

The general configuration and functions of the HEBT remain the same. The bending radius of the HEBT achromat is increased due to the reduced bending dipole field. An extra cell is added to optically match the new linac lattice. Due to these changes, the length of HEBT is increased by about $25 \mathrm{~m}$.

\subsubsection{RTBT}

The configuration and functions of the RTBT remain the same. The length of RTBT is assumed to be the same, provided that the target is relocated about $10 \mathrm{~m}$ closer to the ring. The inscribed diameter of the matching quadrupoles is increased from 26 to $30 \mathrm{~cm}$ due to the increased beta function in the ring straights. 


\section{Impact on the Front End and Linac}

The chopping frequency is reduced from $1.187 \mathrm{MHz}$ to $1.058 \mathrm{MHz}$ for $1 \mathrm{GeV}$ operation, and to $1.098 \mathrm{MHz}$ for $1.3 \mathrm{GeV}$ operation. The filling time is $1.0 \mathrm{~ms}$ for $1 \mathrm{GeV}$ operation. The chopping gap is $300 \mathrm{~ns}$. The chopped pulse length is increased from $546 \mathrm{~ns}$ to $645 \mathrm{~ns}$ for both $1 \mathrm{GeV}$ and $1.3 \mathrm{GeV}$ operation. Table 20 shows major Linac/HEBT interface parameters.

Table 20: Linac requirements and Linac/HEBT interface parameters.

\begin{tabular}{lll}
\hline Quantity & Value & unit \\
\hline Energy, $E_{k}$ & 1000 & $\mathrm{MeV}$ \\
Average current & 2.2 & $\mathrm{~mA}$ \\
Repetition rate & 60 & $\mathrm{~Hz}$ \\
Peak current & 52 & $\mathrm{~mA}$ \\
Chopping frequency & 1.058 & $\mathrm{MHz}$ \\
Filling time & 1.0 & $\mathrm{~ms}$ \\
Chopped pulse length & 645 & $\mathrm{~ns}$ \\
Chopper beam-on duty factor & 68 & $\%$ \\
Linac beam duty factor & 6.0 & $\%$ \\
Emittance (normalized, rms) & 0.45 & $\pi \mathrm{mm} \mathrm{mr}$ \\
Transverse halo (5 $)$ & $10^{-4}$ & \\
Beam energy jitter $(99.99 \%)$ & \pm 2.2 & $\mathrm{MeV}$ \\
Energy spread (rms) & 0.33 & $\mathrm{MeV}$ \\
Beam gap residual & $10^{-4}$ & \\
\hline
\end{tabular}




\section{Impact on the Target}

Pulse length of the beam is increased from 590 to about 695 ns. Pulse frequency is decreased from $1.187 \mathrm{MHz}(842 \mathrm{~ns})$ to $1.058 \mathrm{MHz}(945 \mathrm{~ns})$. Expected transverse profile of the beam remains the same. 


\section{Impact on the Ring WBS}

The total increase in unburdened cost is $\$ 5,337 \mathrm{k}$ for ring, HEBT, and RTBT. 


\section{$6 \quad$ Future Changes for $1.3 \mathrm{GeV}$ Operation}

\subsection{Changes and Benefits}

Comparing with $2 \mathrm{MW}$ operation at $1 \mathrm{GeV}$ beam energy, the same $2 \mathrm{MW}$ operation at 1.3 $\mathrm{GeV}$ requires less beam intensity (reduced from $2.08 \times 10^{14}$ to $1.6 \times 10^{14}$ ). With the same spacecharge tune shift, the ring acceptance to emittance ratio is increased by about a factor of 2 . The uncontrolled beam loss is expected to be reduced.

Although the ring is in principle able to accept $4 \mathrm{MW}$ beam power at $1.3 \mathrm{GeV}$ energy, shielding, engineering protection, and maintainability issues have not been studied. Uncontrolled beam loss is expected to be near $1 \mathrm{~kW}$, exceeding hands-on maintenance condition. Injection foil hits is significantly increased, and foil lifetime is reduced. Finally, feasibility study must be performed on the front end, linac, and target.

Table 21 summarizes the major change of parameter of the ring, HEBT, and RTBT lines from the original hybrid lattice approved in October 1999 to the proposed $1.3 \mathrm{GeV}$-compatible design operating at $1.3 \mathrm{GeV}$.

Table 21: Major change for the SNS ring between the original hybrid lattice (October 1999) and the proposed $1.3 \mathrm{GeV}$-compatible design operating at $1.3 \mathrm{GeV}$ only.

\begin{tabular}{llll}
\hline Quantity & Original & $1.3 \mathrm{GeV}$ & Unit \\
\hline Kinetic energy & 1.0 & 1.3 & $\mathrm{GeV}$ \\
Beam power & 2 & $2-4$ & $\mathrm{MW}$ \\
Circumference & 220.88 & 248.0 & $\mathrm{~m}$ \\
Beam intensity & 2.08 & $1.6-3.3$ & $10^{14}$ \\
Maximum $\beta$ in straight & $19.7,13.6$ & $26.7,16.2$ & $\mathrm{~m}$ \\
Injection foil hit & 6 & $6-9$ & \\
Expected uncontrolled beam loss & $\sim 10^{-4}$ & $1 \sim 2 \times 10^{-4}$ & \\
& 0.2 & $0.2-1$ & $\mathrm{~kW}$ \\
Straight section space & $9.04,2 \times 5.45$ & $12.5,2 \times 6.85$ & $\mathrm{~m}$ \\
Ring dipole field & 0.79 & 0.95 & $\mathrm{kG}$ \\
Ring quad. ID & 21,26 & $21,26,30 \mathrm{~cm}$ & \\
Ring quad. length & $0.5,0.6$ & $0.5,0.55,0.7$ & $\mathrm{~m}$ \\
Injection dipole length increase & - & 40 & $\%$ \\
Extraction Lambertson length increase & - & 15 & $\%$ \\
Extraction kicker module & 14 & 16 & $\mathrm{kV}$ \\
RF voltage $(h=1)$ & 40 & 60 & $\mathrm{MHz}$ \\
RF frequency $(h=1)$ & 1.187 & 1.098 & $\%$ \\
Collimator length increase & - & 60 & $\mathrm{~m}$ \\
\hline HEBT length & 137 & 162 & $\mathrm{~ns}$ \\
Achromat dipole length increase & - & 40 & 645 \\
Proton pulse width on target & 590 & & \\
\hline
\end{tabular}




\subsubsection{Power supplies}

Power supplies must in increased by $20 \%$ to accommodate the increased beam rigidity at 1.3 $\mathrm{GeV}$.

\subsubsection{Injection}

Comparing with $1 \mathrm{GeV}$ operation, for $1.3 \mathrm{GeV}$ operation two injection dipoles need to be

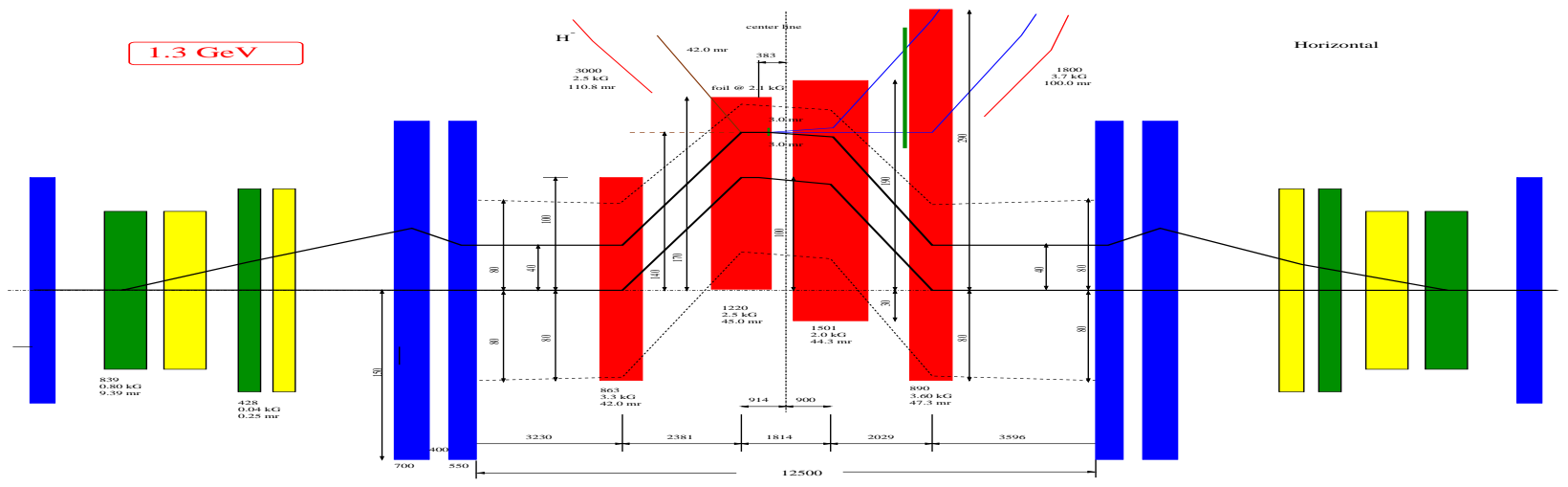

Figure 17: Horizontal schematic layout of the beam injection region of the proposed ring operating at $1.3 \mathrm{GeV}$.

replaced by approximately $40 \%$ longer units operating at reduced (20\%) fields, as shown in Figure 17. The location of the foil mechanism is also changed. Major parameters for the injection magnets are listed in Table 22. The $2.5 \mathrm{kG}$ field of the magnets INJSEPTM1 and

Table 22: Injection DC magnet parameters for the proposed SNS ring operating at $1.3 \mathrm{GeV}$.

\begin{tabular}{lcccccc}
\hline Quantity & INJSEPTM1 & INJBND1 & INJBND2 & INJBND3 & INJBND4 & INJSEPTM2 \\
\hline Kick [mr] & 110.8 & 42.0 & 45.0 & 44.3 & 47.3 & 174.5 \\
Gap (V)[cm] & 6.9 & 23.8 & 23.5 & 23.5 & 23.5 & 6.0 \\
Effective & 306.9 & 87.5 & 122.0 & 150.1 & 90.5 & 220.0 \\
length [cm] & & & & & & \\
No. of turns & 4 & 14 & 28 & 28 & 28 & 8 \\
$B[\mathrm{kG}]$ & 2.44 & 3.26 & 2.5 & 2.0 & 3.54 & 5.4 \\
\hline
\end{tabular}

INJBND2 is chosen to reduce pre-foil stripping of $\mathrm{H}^{-}$ions to a level below $10^{-6}$ per meter, while the $2.0 \mathrm{kG}$ field of the magnet INJBND3 is chosen to minimize the stripping of $n=4$ and lower quantum state $\mathrm{H}^{0}$ ions before the second stripping foil. The foil is located at a field of $2.1 \mathrm{kG}$.

\subsubsection{Collimation}

Due to increased stopping length and increased secondary neutron production, the length of collimation elements needs to be increased by about $60 \%$. 


\subsubsection{RF}

The RF voltage needs to be increased from 40 to $60 \mathrm{kV}$ to accommodate possible beam intensity increase and to compensate for electron cloud effects.

\subsubsection{Extraction}

Two extraction kickers need to be added to the existing extraction system. 


\section{Summary}

With a moderate increase (12\%) of ring circumference and HEBT layout, the ring and transfer lines are designed to be compatible to $1.3 \mathrm{GeV}$ operation. Operating at $1 \mathrm{GeV}$ with $2 \mathrm{MW}$ beam power, the machine is more maintainable and flexible with uncompromised performance. Future operation at $1.3 \mathrm{GeV}$ requires an increase of power supplies (20\%), and changes of injection (two dipoles), collimation, and extraction (two kickers) systems.

The total unburdened cost increase caused by the ring and transfer line re-design from the original hybrid lattice to the proposed $1.3 \mathrm{GeV}$-compatible machine is about $\$ 5,337 \mathrm{k}$. 


\section{References}

[1] Spallation Neutron Source Design Manual, June 1998.

[2] Preliminary Change Request for the SNS Ring Hybrid Lattice, SNS/BNL Technical Note 66, edited by J. Wei, October 1999.

[3] T. Wangler, RF Linear Accelerators, Wiley \& Sons, p. 285.

[4] T. Roser, private communications, 1999.

[5] J. Wei, J. Beebe-Wang, M. Blaskiewicz, P. Cameron, G. Danby, C.J. Gardner, J. Jackson, Y.Y. Lee, H. Ludewig, N. Malitsky, D. Raparia, N. Tsoupas, W.T. Weng, S.Y. Zhang, "Beam-Based Design Optimization for the Spallation Neutron Source Ring" Proceedings of Particle Accelerator Conference, New York (1999) p. 3185.

[6] D. Raparia, SNS/BNL Technical note (to be published).

[7] N. Catalan-Lasheras, et al, Workshop on beam scraping and collimation, 1999 (to be published).

[8] J. Beebe-Wang, et al, Transverse Phase Space Painting For SNS Accumulator Ring Injection, PAC99 (1999) p. 1743.

[9] N. Malitsky, et al, UAL-Based Simulation Environment for Spallation Neutron Source Ring, PAC99 (1999) p. 2713.

[10] A. Fedotov, private communications.

[11] S. Machida, Nucl. Instrum. Methods, A309 (1991) 43.

[12] ORBIT User's Manual, J. Galambos, J. Holmes, D. Olsen, J. Beebe-Wang, A. Luccio (1999).

[13] L. Schachinger, R. Talman, Part. Accel. 22, 35 (1987).

[14] H. Ludewig, et al Collimator Systems for the SNS Ring, PAC99 (1999) p. 548.

[15] R. Witkover, et al, Beam Instrumentation for the Spallation Neutron Source Ring, PAC99 (1999) p. 2250.

[16] M. Blaskiewicz, Instabilities in the SNS, PAC99 (1999) p. 1611.

[17] S.Y. Zhang, SNS Ring Technical Notes 33 (1997), 43 (1998), 61 (1999). 